\title{
European Resuscitation Council Guidelines for Resuscitation 2015 Section 8. Initial management of acute coronary syndromes
}

\author{
Nikolaos I. Nikolaou ${ }^{\mathrm{a}, *}$, Hans-Richard Arntz ${ }^{\mathrm{b}}$, Abdelouahab Bellou ${ }^{\mathrm{c}}$, Farzin Beygui ${ }^{\mathrm{d}}$ \\ Leo L. Bossaert ${ }^{\mathrm{e}}$, Alain Cariou ${ }^{\mathrm{f}}$, on behalf of the Initial management of acute coronary \\ syndromes section Collaborator ${ }^{1}$ \\ ${ }^{a}$ Cardiology Department, Konstantopouleio General Hospital, Athens, Greece \\ ${ }^{\mathrm{b}}$ Department of Emergency Medicine, Charité, University Medicine Berlin, Campus Benjamin Franklin, Berlin, Germany \\ ' University of Rennes, France E Department of Emergency Medicine, Beth Israel Deaconnes Medical Center, Harvard Medical School, \\ Boston, MA, USA \\ d Interventional Cardiology Unit, Caen University Hospital, Caen, France \\ ${ }^{\mathrm{e}}$ Department of Medicine and Health Sciences, University of Antwerp, Antwerp, Belgium \\ ${ }^{\mathrm{f}}$ Medical Intensive Care Unit, Cochin University Hospital (APHP) E Paris Descartes University, Paris, France
}

\section{Summary of main changes since 2010 guidelines}

The following is a summary of the most important views and changes in new recommendations for the diagnosis and treatment of acute coronary syndromes (ACS) since the last ERC guidelines in 2010.

\section{Diagnostic interventions in ACS}

- Pre-hospital recording of a 12-lead electrocardiogram (ECG) is recommended in patients with suspected ST segment elevation acute myocardial infarction (STEMI). For those with STEMI this expedites prehospital and in-hospital reperfusion and reduces mortality for both those planned for primary percutaneous coronary intervention (PPCI) and those who receive fibrinolytic therapy.

- Non-physician ECG STEMI interpretation with or without the aid of computer interpretation is suggested if adequate diagnostic performance can be maintained through carefully monitored quality assurance programs.

- Pre-hospital STEMI activation of the catheterisation laboratory may not only reduce treatment delays but may also reduce patient mortality.

- The use of negative high-sensitivity cardiac troponins (hs-cTn) during initial patient evaluation cannot be used as a standalone measure to exclude an ACS, but in patients with very low risk scores may justify early discharge.

\section{Therapeutic interventions in ACS}

- Adenosine diphosphate (ADP) receptor antagonists (clopidogrel, ticagrelor, or prasugrel-with specific restriction), may be given

\footnotetext{
* Corresponding author.

E-mail address: nikosnik@otenet.gr (N.I. Nikolaou).

1 The Initial management of acute coronary syndromes section Collaborator is listed in the Collaborator section.
}

either pre-hospital or in the ED for STEMI patients planned for primary $\mathrm{PCI}$.

- Unfractionated heparin (UFH) can be administered either in the pre-hospital or in-hospital setting in patients with STEMI and a planned primary $\mathrm{PCI}$ approach.

- Pre-hospital enoxaparin may be used as an alternative to prehospital UFH for STEMI.

- Patients with acute chest pain with presumed ACS do not need supplemental oxygen unless they present with signs of hypoxia dyspnoea, or heart failure.

\section{Reperfusion decisions in STEMI}

- Reperfusion decisions have been reviewed in a variety of possible local situations.

- When fibrinolysis is the planned treatment strategy, we recommend using pre-hospital fibrinolysis in comparison to in-hospital fibrinolysis for STEMI where transport times are $>30 \mathrm{~min}$ and pre-hospital personnel are well trained.

- In geographic regions where PCI facilities exist and are available, direct triage and transport for $\mathrm{PCI}$ is preferred to pre-hospital fibrinolysis for STEMI.

- Patients presenting with STEMI in the emergency department (ED) of a non-PCI capable hospital should be transported immediately to a $\mathrm{PCI}$ centre provided that treatment delays for $\mathrm{PPCI}$ are less than $120 \mathrm{~min}$ (60 to $90 \mathrm{~min}$ for early presenters and those with extended infarctions), otherwise patients should receive fibrinolysis and be transported to a PCI centre.

- Patients who receive fibrinolytic therapy in the emergency department of a non-PCI centre should be transported if possible for early routine angiography (within 3 to $24 \mathrm{~h}$ from fibrinolytic therapy) rather than be transported only if indicated by the presence of ischemia.

- $\mathrm{PCI}$ in less than $3 \mathrm{~h}$ following administration of fibrinolytics is not recommended and can be performed only in case of failed fibrinolysis. 
Hospital reperfusion decisions after return of spontaneous circulation (ROSC)

- We recommend emergency cardiac catheterisation lab evaluation (and immediate PCI if required), in a manner similar to patients with STEMI without cardiac arrest, in selected adult patients with ROSC after out-of-hospital cardiac arrest (OHCA) of suspected cardiac origin with ST-elevation on ECG.

- In patients who are comatose and with ROSC after OHCA of suspected cardiac origin without ST-elevation on ECG It is reasonable to consider an emergency cardiac catheterisation lab evaluation in patients with the highest risk of coronary cause cardiac arrest.

\section{Introduction}

The incidence of acute ST-elevation myocardial infarction (AMI) is decreasing in many European countries; ${ }^{1}$ however, the incidence of non-STEMI acute coronary syndrome (non-STEMI ACS) is increasing. ${ }^{2}$ Although in-hospital mortality from STEMI has been reduced significantly by modern reperfusion therapy and improved secondary prophylaxis, the overall 28-day mortality is virtually unchanged because about two thirds of those who die do so before hospital arrival, mostly from lethal arrhythmias triggered by ischaemia. ${ }^{3}$ Thus, the best way of improving survival from an ischaemic attack is reducing the delay from symptom onset to first medical contact and targeted treatment started in the early out-of hospital phase.

The term acute coronary syndrome (ACS) encompasses three different entities of the acute manifestation of coronary heart disease (Fig. 8.1): ST elevation myocardial infarction (STEMI), non-ST elevation myocardial infarction and unstable angina pectoris (UAP). Non-ST elevation myocardial infarction and UAP are usually combined in the term non-STEMI-ACS. The common pathophysiology of ACS is a ruptured or eroded atherosclerotic plaque. ${ }^{4}$ Electrocardiographic (ECG) characteristics (absence or presence of ST elevation) differentiate STEMI from non-STEMI ACS. The latter may present with ST segment depression, nonspecific ST segment wave abnormalities, or even a normal ECG. In the absence of ST elevation, an increase in the plasma concentration of cardiac biomarkers, particularly troponin $\mathrm{T}$ or I as the most specific markers of myocardial cell necrosis, indicates non-STEMI.

Acute coronary syndromes are the commonest cause of malignant arrhythmias leading to sudden cardiac death. The therapeutic goals are to treat acute life-threatening conditions, such as ventricular fibrillation (VF) or extreme bradycardia, and to preserve left ventricular function and prevent heart failure by minimising the extent of myocardial damage. The current guidelines address the first hours after onset of symptoms. Out-of-hospital treatment and initial therapy in the emergency department (ED) may vary according to local capabilities, resources and regulations. The data supporting out-of-hospital treatment are often extrapolated from studies of initial treatment after hospital admission; there are few high-quality out-of-hospital studies. The European Society of Cardiology and the American College of Cardiology/American Heart Association have published comprehensive guidelines for the diagnosis and treatment of ACS with and without ST elevation. The current recommendations are in line with these guidelines. 5,6

\section{Diagnosis and risk stratification in acute coronary syndromes}

Signs and symptoms of ACS

Typically ACS appears with symptoms such as radiating chest pain, shortness of breath and sweating; however, atypical

\section{Patient with clinical signs and symptoms of ACS}

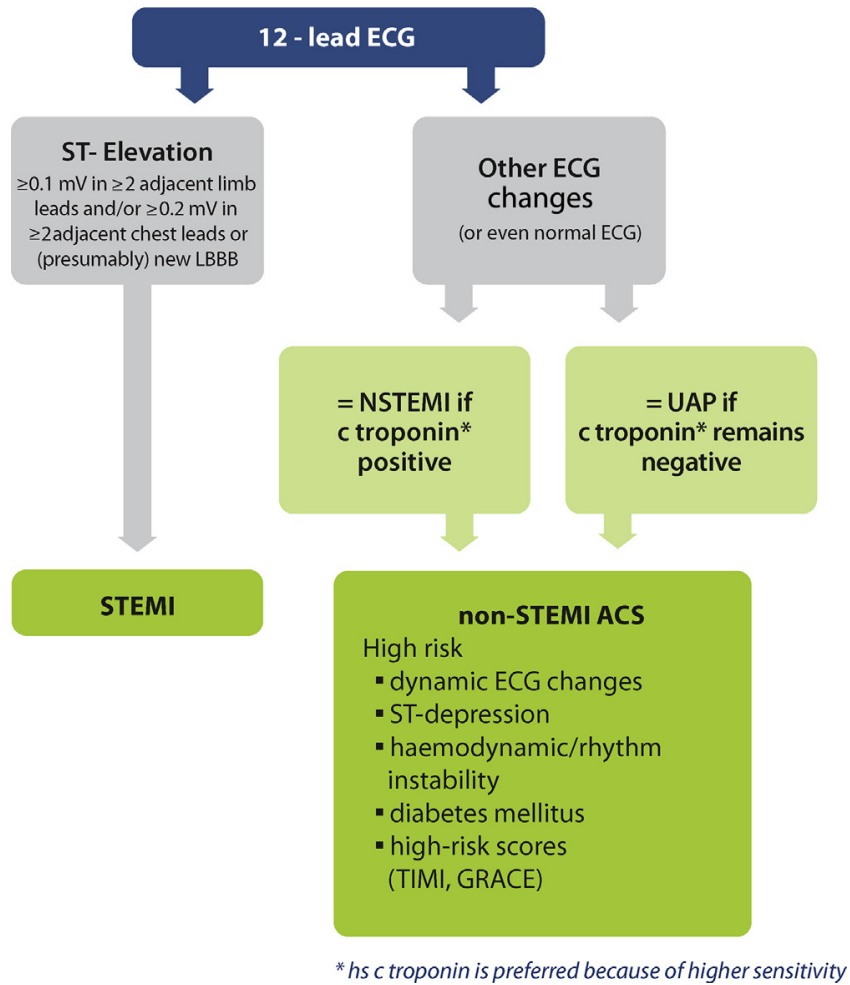

Fig. 8.1. Definitions of acute coronary syndromes (ACS); ECG, electrocardiogram; LBBB, left bundle branch block; STEMI, ST-elevation myocardial infarction; NSTEMI, non-ST-elevation myocardial infarction; c troponin, cardiac troponin; UAP, unstable angina pectoris; TIMI, thrombolysis in acute myocardial infarction; GRACE, global registry of acute coronary events.

symptoms or unusual presentations may occur in the elderly, in females, and in diabetics. None of these signs and symptoms of ACS can be used alone for the diagnosis of ACS. A reduction in chest pain after nitroglycerin administration can be misleading and is not recommended as a diagnostic manoeuvre. ${ }^{7}$ Symptoms may be more intense and last longer in patients with STEMI but are not reliable for discriminating between STEMI and non-STEMI-ACS..$^{5,8-10}$

The patient's history should be evaluated carefully during first contact with healthcare providers. It may provide the first clues for the presence of an ACS, trigger subsequent investigations and, in combination with information from other diagnostic tests, can help in making triage and therapeutic decisions in the out-of hospital setting and the emergency department (ED).

The clinical recognition of ACS is a challenge emphasising that training of emergency providers including EMS dispatchers, doctors and non-doctors depending on the type of EMS system is essential. Clinical pathway protocols are strongly recommended and must be available for emergency teams working in the pre hospital setting and the emergency department (ED).

\section{2-lead ECG}

A 12-lead ECG is the key investigation for assessment of an ACS. In the case of STEMI, it indicates the need for immediate reperfusion therapy (i.e. primary percutaneous coronary intervention (PCI) or pre-hospital fibrinolysis). When an ACS is suspected, printout of a 12-lead-ECG should be acquired and interpreted as soon as possible after first patient contact, to facilitate earlier diagnosis and triage. $6,8,10$ STEMI is typically diagnosed when ST-segment 
elevation, measured at the J point, fulfills specific voltage criteria in the absence of left ventricular (LV) hypertrophy or left bundle branch block (LBBB). ${ }^{5}$ In patients with clinical suspicion of ongoing myocardial ischaemia with new or presumed new LBBB, consider prompt reperfusion therapy, preferably using primary $\mathrm{PCI}(\mathrm{PPCI})$. Ventricular pacing may also mask the presence of an evolving MI and may require urgent angiography to confirm diagnosis and initiate therapy.

Right precordial leads should be recorded in all patients with inferior STEMI in order to detect right ventricular MI. Isolated STdepression $\geq 0.05 \mathrm{mV}$ in leads V1 through V3 represents STEMI in the inferobasal portion of the heart which may be confirmed by ST segment elevation in posterior leads (V7-V9). Pre-hospital or ED ECG yields useful diagnostic information when interpreted by trained health care providers.

Recording of a 12-lead ECG out-of-hospital enables advanced notification to the receiving facility and expedites treatment decisions after hospital arrival. In many studies, using pre-hospital 12-lead ECG, the time from hospital admission to initiating reperfusion therapy is reduced by 10 to $60 \mathrm{~min}$. This is associated with shorter times to reperfusion and improved patient survival in both patients with $\mathrm{PCI}$ and those undergoing fibrinolysis. ${ }^{11-19}$

Trained EMS personnel (emergency physicians, paramedics and nurses) can identify STEMI, defined by ST elevation of $\geq 0.1 \mathrm{mV}$ elevation in at least two adjacent limb leads or $>0.2 \mathrm{mV}$ in two adjacent precordial leads, with a high specificity and sensitivity comparable to diagnostic accuracy in the hospital. ${ }^{20,21}$ It is thus reasonable that paramedics and nurses be trained to diagnose STEMI without direct medical consultation, as long as there is strict concurrent provision of quality assurance.

If interpretation of the pre-hospital ECG is not available on-site, computer interpretation ${ }^{22,23}$ or field transmission of the ECG is reasonable. ${ }^{14,22-29}$ Recording and transmission of diagnostic quality ECGs to the hospital usually takes less than $5 \mathrm{~min}$. When used for the evaluation of patients with suspected ACS, computer interpretation of the ECG may increase the specificity of diagnosis of STEMI, especially for clinicians inexperienced in reading ECGs. The benefit of computer interpretation however, is dependent on the accuracy of the ECG report. Incorrect reports may mislead inexperienced ECG readers. Thus computer-assisted ECG interpretation should not replace, but may be used as an adjunct to, interpretation by an experienced clinician.

\section{Biomarkers, rules for early discharge and chest pain observation protocols}

In the absence of ST elevation on the ECG, the presence of a suggestive history and elevated concentrations of biomarkers (troponins, CK and CKMB) characterise non-STEMI and distinguish it from STEMI and unstable angina, respectively. Measurement of a cardiac-specific troponin is used routinely because of its higher sensitivity and specificity. Elevated concentrations of troponin are particularly helpful in identifying patients at increased risk of adverse outcome. ${ }^{30,31}$

In order to use the measured biomarker optimally, clinicians should be familiar with the sensitivity, precision and institutional norms of the assay, and also the release kinetics and clearance. Highly sensitive (ultrasensitive) cardiac troponin assays have been developed. They can increase sensitivity and accelerate diagnosis of MI in patients with symptoms suspicious of cardiac ischaemia. ${ }^{32}$

Cardiac biomarker testing should be part of the initial evaluation of all patients presenting to the ED with symptoms suggestive of cardiac ischaemia. However, the delay in release of biomarkers from damaged myocardium prevents their use in diagnosing myocardial infarction in the first hours after the onset of symptoms. For patients who present within $6 \mathrm{~h}$ of symptom onset, and have an initial negative cardiac troponin, biomarkers should be measured again between 2 and 3 and up to $6 \mathrm{~h}$ later for hs-cTn ( $12 \mathrm{~h}$ with regular troponin). The majority of patients with possible ACS do not have an ACS but the identification of those with ACS is challenging. The recently reported rate of patients with a 'missed' diagnosis of ACS in the ED is up to $3.5 \%$ with significant morbidity and mortality. ${ }^{33-35}$

With the implementation of high-sensitivity (hs)-assays, many hs-cTn based pathways for rapid decision-making have been tested which resulted in a proliferation of proposed diagnostic algorithms in the ED including ECG, troponin, and TIMI risk score. Data from large observational multicentre studies showed an excellent performance of $2 \mathrm{~h}$ rule-out protocols that combine hs-cTn values with clinical information, but also for a $1 \mathrm{~h}$ rule-out and rule-in protocol exclusively based on hs-cTnT values. ${ }^{36-39}$

It is not recommended to use high sensitivity cardiac troponins as a stand-alone measure at 0 and $2 \mathrm{~h}$ to exclude the diagnosis of ACS, defined as < 1\% 30-day major adverse cardiac events (MACE). ${ }^{40}$ Negative hs-cTnI measured at 0 and $2 \mathrm{~h}$ may be used together with low risk stratification (TIMI score of 0 or 1 ) to exclude the diagnosis of ACS. Also negative cTnI or cTnT measured at 0 and 3-6 $\mathrm{h}$ together may be used in conjunction with very low risk stratification (Vancouver score of 0 or North American CP score of 0 and age $<50$ ) to exclude the diagnosis of ACS.

There is no evidence to support the use of troponin point-ofcare testing (POCT) in isolation as a primary test in the pre-hospital setting to evaluate patients with symptoms suspicious of cardiac ischaemia. $^{32}$ In the ED, use of point-of-care troponin assays may help to shorten time to treatment and length of ED stay. ${ }^{41}$ Until further randomised control trials are performed, other serum assays should not be considered first-line steps in the diagnosis and management of patients presenting with ACS symptoms. ${ }^{42-44}$

Risk assessment scores and clinical prediction algorithms using clinical history, physical examination, ECG, and cardiac troponins have been developed to help identify patients with ACS at increased risk of adverse outcome(s). Both accurate discrimination and calibration are needed from a risk prediction equation. Clinicians need to know which ACS patients are at highest risk so they can be prioritised for earlier and more aggressive treatment. But they also need to know what the absolute risk is, so patients can be advised about the risk and benefits of various treatment options, and to support them in making rational cost-benefit decisions. Global Registry of Acute Coronary Events (GRACE) and Thrombolysis In Myocardial Infarction (TIMI) risk score are the most commonly used. In a recent meta-analysis, TIMI and GRACE risk scores were the only ones validated in multiple clinical setting, with GRACE showing a better performance with an area under the curve (AUC) around 0.85 .45

The GRACE score identified a sizable low-risk cohort potentially safe for early ED discharge with outpatient assessment with high sensitivity and negative predictive value; however the complexity of this tool may limit its utility. ${ }^{46,47}$ It could be difficult to use these scores in the context of a pre-hospital setting where biological parameters (biomarkers and creatinine) are not available. This is probably the reason why little attention has been focused on the pre-hospital aspects of care in non-STEMI despite its commonality and dominant role as the major overall contributor to mortality from myocardial infarction. Whether implementation of a prehospital regional program of early-risk stratification, initiation of evidence-based care, and a timely invasive strategy delivered to patients with non-STEMI at moderate to high risk would enhance outcomes still needs investigation. ${ }^{48}$ The new version of the GRACE risk score (GRACE 2.0) uses non-linear functions and seems to be more accurate than the original version. It is now validated over the longer term (to 1 and 3 years) and with substitutions possible for creatinine values and Killip class GRACE 2.0 will enable risk stratification at the patient presentation wherever the management care will start. ${ }^{49}$ 


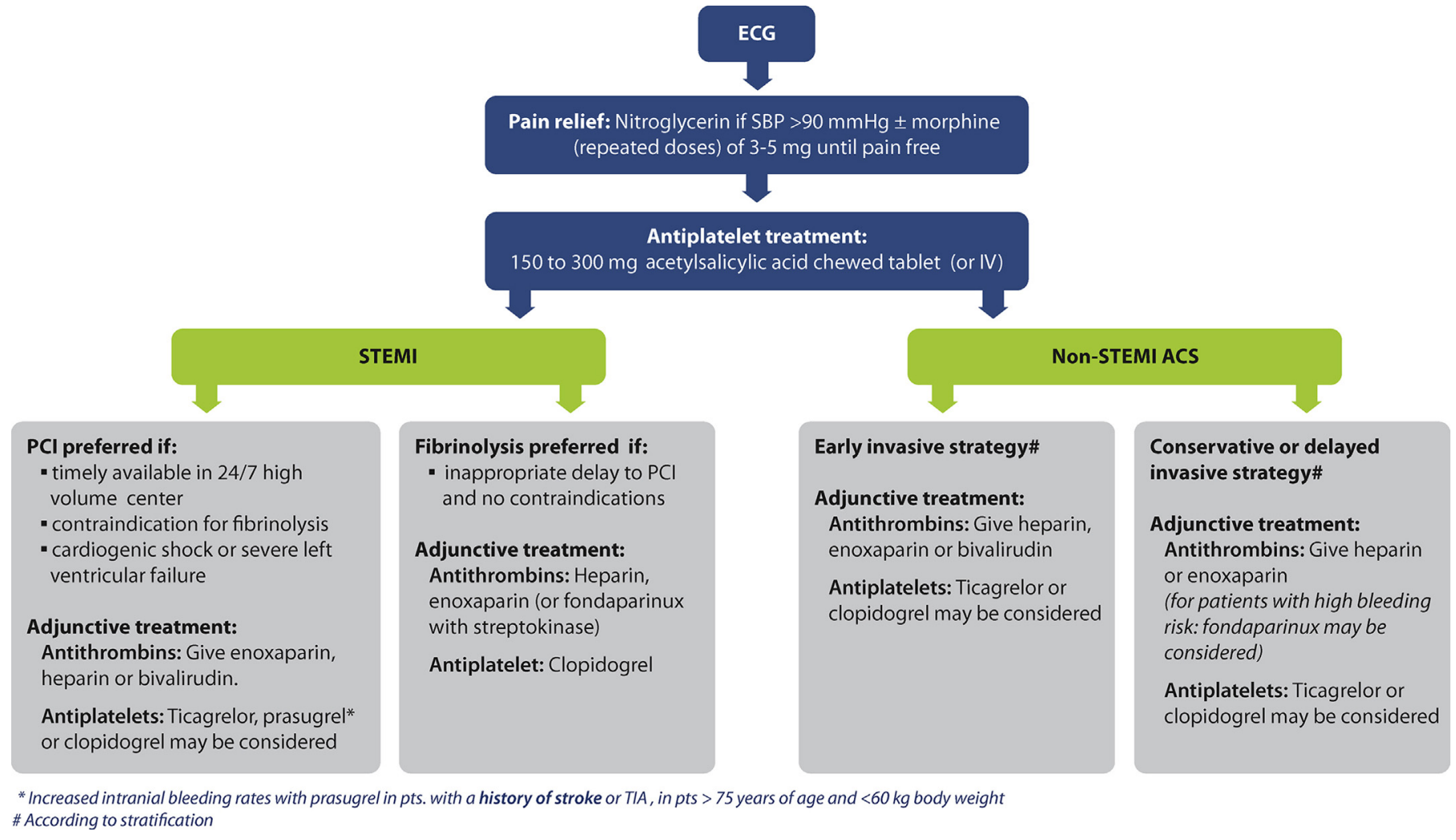

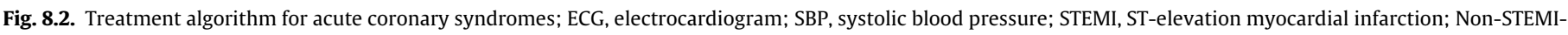
ACS, non-ST-elevation acute coronary syndrome; PCI, percutaneous coronary intervention.

In patients suspected of an ACS the combination of an unremarkable past history and physical examination with negative initial ECG and biomarkers cannot be used to exclude ACS reliably. Therefore a follow up period is mandatory in order to reach a diagnosis and make therapeutic decisions.

Chest pain observation protocols are rapid systems for assessment of patients with suspected ACS. They should generally include a history and physical examination, followed by a period of observation, during which serial electrocardiography and cardiac marker measurements are performed. At some point after AMI is excluded, the evaluation of the patient should be complemented by either a non-invasive evaluation for anatomical coronary disease or provocative testing for inducible myocardial ischaemia. These protocols may be used to improve accuracy in identifying patients requiring inpatient admission or further diagnostic testing while maintaining patient safety, reducing length of stay and reducing costs. ${ }^{50}$

In patients presenting to the ED with a history suggestive of ACS, but normal initial workup, chest pain (observation) units may represent a safe and effective strategy for evaluating patients. The potential therapeutic and diagnostic yield of provocative testing may take on an increasingly central role in determining the usefulness of provocative testing for low-risk and moderate-risk patients with chest pain evaluated in accelerated diagnostic protocols. Multicentre studies are needed to demonstrate the impact of chest pain (observation) units in the use of provocative testing. ${ }^{51}$ They may be recommended as a means to reduce length of stay, hospital admissions and healthcare costs, improve diagnostic accuracy and improve quality of life. ${ }^{52}$ There is no direct evidence demonstrating that chest pain units or observation protocols reduce adverse cardiovascular outcomes, particularly mortality, for patients presenting with possible ACS.

\section{Imaging techniques}

Effective screening of patients with suspected ACS, but with negative ECG and negative cardiac biomarkers, remains challenging. Non invasive imaging techniques (CT angiography, ${ }^{53}$ cardiac magnetic resonance, myocardial perfusion imaging, ${ }^{54}$ and echocardiography ${ }^{55}$ ) have been evaluated as means of screening these low-risk patients and identifying subgroups that can be discharged home safely. ${ }^{31,56-58}$ Furthermore, differential diagnoses such as aortic dissection, pulmonary embolism, aortic stenosis, hypertrophic cardiomyopathy, pericardial effusion, or pneumothorax may be identified. Therefore, echocardiography should be routinely available in ED, and used in all patients with suspected ACS. Studies are needed to evaluate the impact of echocardiography in the pre-hospital setting. Although there are no large multicentre trials, existing evidence indicates that these diagnostic modalities enable early and accurate diagnosis with a reduction in length of stay and costs without increasing cardiac events. Both the exposure to radiation and iodinated contrast should be considered when using myocardial perfusion imaging and multi-detector computer tomography coronary angiography (MDCTCA).

MDCTCA has been recently proposed in the management acute chest pain in the ED. It is accurate compared with invasive coronary angiography, enabling differential diagnosis, and it is feasible and practical in the ED. ${ }^{53,59-63}$ MDCTCA has a high ability to rule out obstructive coronary artery disease (CAD) ${ }^{64,65}$ Early use of cardiac MDCTCA in patients presenting to the ED with chest pain and a low to intermediate risk of ACS quickly identifies a group of particularly low-risk patients ( $<1 \%$ risk of adverse events within 30 days) and enables safe and expedited discharge. By preventing unnecessary admissions and prolonged lengths of stay, a strategy based on early cardiac MDCTCA has been shown to be efficient. ${ }^{66-68}$ In a significant 
number of low-risk ACS patients, MDCTCA detects severe coronary lesions and enables dedicated further diagnostic and therapeutic intervention. In a recent meta-analysis, MDCTCA demonstrated a high sensitivity and a low negative likelihood ratio of 0.06 , and was effective in ruling out the presence of ACS in low to intermediate risk patients presenting to the ED with acute chest pain. ${ }^{69}$ But the inability of anatomical findings to prove the presence of ischaemia, the cancer risk induced by radiation exposure and potential overuse still raise concerns about the relevance of this strategy.

\section{Treatment of acute coronary syndromes-Symptoms}

\section{Nitrates}

Glyceryl trinitrate is an effective treatment for ischaemic chest pain and has beneficial haemodynamic effects, such as dilation of the venous capacitance vessels, dilation of the coronary arteries and, to a minor extent, the peripheral arteries. Glyceryl trinitrate may be considered if the systolic blood pressure (SBP) is above $90 \mathrm{mmHg}$ and the patient has ongoing ischaemic chest pain (Fig. 8.2). Glyceryl trinitrate can also be useful in the treatment of acute pulmonary congestion. Do not use nitrates in patients with hypotension $(\mathrm{SBP} \leq 90 \mathrm{mmHg})$, particularly if combined with bradycardia, and in patients with inferior infarction and suspected right ventricular involvement. Use of nitrates under these circumstances can decrease the blood pressure and cardiac output. Do not use nitrates if $5^{\prime}$-phosphodiesterase inhibitors have been used recently $(<48 \mathrm{~h})$. $^{5,9,70,71}$

Give glyceryl trinitrate $0.4 \mathrm{mg}$ sublingual or equivalent every 5 min up to 3 doses as SBP allows. Begin IV dosing at 1010 micrograms $\mathrm{min}^{-1}$ in persistent pain or pulmonary edema; titrate to desired BP effect.

\section{Analgesia}

Morphine is the analgesic of choice for nitrate-refractory pain and also has calming effects on the patient making sedatives unnecessary in most cases. Since morphine is a dilator of venous capacitance vessels, it may have additional benefit in patients with pulmonary congestion. Give morphine in initial doses of 3-5 mg intravenously and repeat every few min until the patient is pain-free. Caution is needed in presence of lethargy, hypotension, bradycardia or known hypersensitivity. 5,9,71 Avoid non-steroidal anti-inflammatory drugs (NSAIDs) for analgesia because they have pro-thrombotic effects. ${ }^{72}$

\section{Oxygen}

Evidence is accumulating about the questionable role of supplemental oxygen in cardiac arrest, after ROSC and in acute coronary syndromes. Patients with acute chest pain with presumed ACS do not need supplemental oxygen unless they present with signs of hypoxia, dyspnoea or heart failure. There is increasing evidence suggesting that hyperoxia may be harmful in patients with uncomplicated myocardial infarction. ${ }^{73-76}$

In ACS complicated with cardiac arrest, hypoxia develops rapidly. Ischaemic brain injury is a major determinant for neurologically intact survival. Therefore during CPR adequate oxygenation is essential. After ROSC, avoid both hypoxia and hyperoxia (see post resuscitation care). ${ }^{77}$ Use $100 \%$ inspired oxygen until the arterial oxygen saturation can be measured reliably. As soon as the arterial blood oxygen saturation can be measured reliably, titrate the inspired oxygen concentration to achieve arterial blood oxygen saturation in the range of $94-98 \%$, or $88-92 \%$ in chronic obstructive pulmonary disease. .,71 $^{5,7}$

\section{Treatment of acute coronary syndromes-Cause}

\section{Inhibitors of platelet aggregation}

Platelet activation and aggregation following atherosclerotic plaque rupture are central pathophysiologic mechanisms of acute coronary syndromes and antiplatelet therapy is a pivotal treatment of ACS whether with or without ST segment elevation, with or without reperfusion and with or without revascularisation.

\section{Acetylsalicylic acid (ASA)}

Large randomised controlled trials indicate decreased mortality when ASA (75-325 mg) is given to hospitalised patients with ACS independent of the reperfusion or revascularisation strategy. A few studies have suggested reduced mortality if ASA is given earlier. ${ }^{78-80}$ Therefore, give an oral loading dose of ASA (150 to $300 \mathrm{mg}$ of a non-enteric coated formulation) or $150 \mathrm{mg}$ of an IV preparation as soon as possible to all patients with suspected ACS unless the patient has a known true allergy to ASA or has active bleeding. ASA may be given by the first healthcare provider, bystander or by dispatcher assistance according to local protocols.

\section{$A D P$ receptor inhibitors}

The inhibition of the platelet ADP receptor by the thienopyridines clopidogrel and prasugrel (irreversible inhibition) and the cyclo-pentyl-triazolo-pyrimidine ticagrelor (reversible inhibition) leads to further inhibition of platelet aggregation in addition to that produced by ASA. In contrast to clopidogrel, the effect of prasugrel and ticagrelor are largely independent of a genetically determined variability of drug metabolism and activation. Therefore prasugrel and ticagrelor (reversible) lead to a more reliable, faster and stronger inhibition of platelet aggregation.

A large randomised study comparing a loading dose of $300 \mathrm{mg}$ clopidogrel followed by $75 \mathrm{mg}$ daily with prasugrel (loading dose $60 \mathrm{mg}$, followed by $10 \mathrm{mg}$ daily) in patients with ACS (see specific remarks on non-STEMI-ACS below) planned for PCI resulted in fewer MACE with prasugrel; the bleeding rate was higher, however. Bleeding risk was increased markedly in patients weighing less than $60 \mathrm{~kg}$ and those older than 75 years. ${ }^{81}$ A significantly increased intracranial bleeding rate was observed in patients with a history of transient ischaemic attack (TIA) and/or stroke in association with prasugrel. In another study, ticagrelor (loading dose $180 \mathrm{mg}$, followed by $90 \mathrm{mg}$ twice daily) proved to be superior to clopidogrel (loading dose 300-600 mg followed by $75 \mathrm{mg}$ daily) with respect to mortality and MACE in the general setting of ACS but also associated with higher risks of bleeding. ${ }^{82}$

\section{ADP-receptor inhibitors in non-STEMI-ACS.}

Clopidogrel. If given in addition to heparin and ASA in highrisk non-STEMI-ACS patients, clopidogrel improves outcome. ${ }^{83}$ If a conservative approach is selected, give a loading dose of $300 \mathrm{mg}$; with a planned PCI strategy, an initial dose of $600 \mathrm{mg}$ may be preferred. There is no large-scale study investigating pre-treatment with clopidogrel, compared with peri-interventional application either with a $300 \mathrm{mg}$ or $600 \mathrm{mg}$ loading dose.

Prasugrel. Prasugrel (60 mg loading dose) may be given to patients with high-risk non-STEMI-ACS and planned PCI only after angiography, provided that coronary stenoses are suitable for $\mathrm{PCI}$. Contraindications (history of TIA/stroke) and the benefit - risk balance in patients with high bleeding risk (weight $<60 \mathrm{~kg}$, age $>75$ years) should be considered. A RCT, comparing pre versus postangiography treatment by prasugrel in non-STEMI-ACS showed that pre-treatment was associated with higher risk of major bleeding without reducing thrombotic events excluding prasugrel from 
any possible pre-treatment strategy in non-STEMI-ACS whether initiated in or out of hospital before coronary anatomy is known. ${ }^{84}$

Ticagrelor. According to the latest ESC guidelines, ${ }^{6}$ ticagrelor (180 mg loading dose) should be given in addition to ASA in all patients with moderate to high-risk non-STEMI-ACS whether an invasive strategy is planned or not. In patients with non-STEMI-ACS planned for a conservative approach, give ticagrelor or clopidogrel as soon as the diagnosis is confirmed. There is insufficient evidence to recommend for or against pre-treatment with these agents when $\mathrm{PCI}$ is the initial strategy.

\section{ADP-receptor inhibitors in STEMI.}

Clopidogrel. Pre-hospital versus in-hospital administration of clopidogrel has been assessed in two small studies which have shown its safety but no evident clinical benefit. ${ }^{85,86}$ However, a meta-analysis of pre-PCI versus post-PCI (and not pre-hospital versus in-hospital) administration of clopidogrel in STEMI subgroup of patients has shown a significant benefit in terms of mortality reduction and MI rates without a bleeding excess risk in association with pre-treatment. ${ }^{87}$ Although there is no large study on the use of clopidogrel for pre-PCI treatment of patients presenting with STEMI and planned PCI, it is likely that this strategy is beneficial. Since platelet inhibition is more profound with a higher dose, a $600 \mathrm{mg}$ loading dose given as soon as possible may be considered for patients presenting with STEMI and planned PCI.

Two large randomised trials studied clopidogrel compared with placebo in patients with STEMI treated conservatively or with fibrinolysis. ${ }^{88-90}$ One study included patients up to 75 years, treated with fibrinolysis, ASA, an anti-thrombin and a loading dose of $300 \mathrm{mg}$ clopidogrel. ${ }^{88}$ Treatment with clopidogrel resulted in fewer occluded culprit coronary arteries at angiography and fewer reinfarctions, without an increased bleeding risk. The other study investigated STEMI patients without age limits to be treated conservatively or with fibrinolysis. In this trial, clopidogrel (no loading, $75 \mathrm{mg}$ daily) compared with placebo resulted in fewer deaths and a reduction of the combined endpoint of death and stroke. ${ }^{89}$ Therefore patients with STEMI treated with fibrinolysis should be treated with clopidogrel ( $300 \mathrm{mg}$ loading dose up to an age of 75 years and $75 \mathrm{mg}$ without loading dose if $>75$ years of age) in addition to ASA and an antithrombin.

Prasugrel. Prasugrel with a loading dose of $60 \mathrm{mg}$ up to $24 \mathrm{~h}$ before, at the time of, or even after, PCI may be given in addition to ASA and an antithrombin to patients presenting with STEMI with planned PCI. ${ }^{91}$ Contraindications (history of TIA/stroke), and relation of bleeding risk versus benefit in patients with a body weight $<60 \mathrm{~kg}$ or aged $>75$ years should be taken into account. There is no data on prehospital treatment with prasugrel and no data on prasugrel if used in the context of fibrinolysis.

Ticagrelor. Ticagrelor may be given with a loading dose of $180 \mathrm{mg}$ to patients presenting with STEMI and planned PCI. The benefit of pre-hospital versus in-catheterisation laboratory administration of ticagrelor (180 mg loading dose) was assessed in a RCT including 1862 STEMI patients presenting within $6 \mathrm{~h}$ after symptom onset and planned for primary PCI. The study showed no benefit in terms of angiographic coronary artery flow or ST segment elevation resolution (primary end-point) or major clinical endpoints. The study also showed that pre-hospital administration of ticagrelor was associated with a reduced rate of definite acute stent thrombosis (OR 0.19, 95\% CI 0.04-0.86) without excess in the risk of bleeding. ${ }^{92}$ However, this end-point was not pre-specified and the finding should be considered as hypothesis generating only. There are no data on ticagrelor when used in the context of fibrinolysis.

The relative benefit of pre-hospital administering an ADP antagonist routinely in patients planned for PCI for STEMI may be marginal and offset by additional harms that should be evaluated in larger RCTs that include additional patient-oriented outcomes.
However, the use of ADP antagonists in patients transferred for primary PCI may be considered after cautious evaluation of the risk-benefit balance for each patient.

\section{Glycoprotein (Gp) IIB/IIIA inhibitors}

Glycoprotein (Gp) IIB/IIIA receptor activation is the common final link of platelet aggregation. Eptifibatide and tirofiban lead to reversible inhibition, while abciximab leads to irreversible inhibition of the Gp IIB/IIIA receptor. Older studies from the prestent era mostly support the use of this class of drugs. ${ }^{93}$ Recent studies mostly document neutral or worse outcomes ${ }^{94}$ with the exception of the recently published ON-TIME- 2 trial comparing pre-hospital systematic versus in-hospital provisional administration of tirofiban associated with secondary PCI and showing a benefit of pre-treatment with Gp IIB/IIIA receptor blockers on the primary thrombotic endpoint with no relevant excess in bleeding risk..$^{95}$ Also a recent meta-analysis studying the results of 7 randomised trials including 722 patients comparing early versus late administration of abciximab in the setting of primary PCI for STEMI showed a benefit of early strategy on coronary artery patency translating to a benefit in terms of mortality. ${ }^{96}$ However, in almost all supporting, neutral or opposing studies, bleeding occurred in more patients treated with Gp IIB/IIIA receptor blockers. There are insufficient data to support routine pre-treatment with Gp IIB/IIIA receptor blockers in patients with STEMI or non-STEMI-ACS. It is not recommended to give Gp IIB/IIIA receptor blockers before coronary anatomy is known. For high-risk patients with non-STEMI-ACS, in-hospital pre-treatment with eptifibatide or tirofiban may be acceptable whereas abciximab may be given only in the context of $\mathrm{PCI}$. Taking into account the increased bleeding risk with GpIIB/IIIA receptor blockers when used with heparins, alternative treatment strategies with the use of ADP antagonists should be considered. ${ }^{97}$

\section{Antithrombins}

Unfractionated heparin (UFH) is an indirect inhibitor of thrombin, which in combination with ASA is used as an adjunct with fibrinolytic therapy or PPCI and is an important part of treatment of unstable angina and STEMI. Limitations of unfractionated heparin include its unpredictable anticoagulant effect in individual patients, the need to give it intravenously and the need to monitor aPTT. Moreover, heparin can induce thrombocytopaenia. Since publication of the 2010 ERC guidelines on ACS, several randomised trials have been performed testing alternative antithrombins versus UFH for the treatment of patients with ACS. ${ }^{98-100}$ These alternatives are characterised by a more specific factor Xa activity (low molecular weight heparins [LMWH], fondaparinux) or are direct thrombin inhibitors (bivalirudin). With the latter antithrombins, the coagulation system does not need be monitored and the risk of thrombocytopenia is reduced. There are no studies evaluating prehospital versus delayed in-hospital administration of anti-thrombins other than UFH. Rivaroxaban, apixaban and other oral direct thrombin antagonists may have an indication after stabilisation in specific patient groups but not in the initial treatment of ACS. ${ }^{101}$

\section{Antithrombins in non-STEMI-ACS}

Parenteral anticoagulation, in addition to anti-platelet drugs, is recommended at the time of diagnosis because it effectively reduces the rate of MACE in patients with non-STEMI-ACS. Even if there is a rationale in use of early treatment to avoid MACE, there is no scientific proof of superiority of pre-hospital over in-hospital initiation of anti-thrombin therapy.

Compared with UFH (70-100 $\mathrm{IU} \mathrm{kg}^{-1} \mathrm{IV}$ ), enoxaparin (30 mg IV followed by $1 \mathrm{mg} \mathrm{kg}^{-1}$ every $12 \mathrm{~h}$ ) reduces the combined 
endpoint of mortality, myocardial infarction and the need for urgent revascularisation, if given within the first $24-36 \mathrm{~h}$ of onset of symptoms of non-STEMI-ACS. ${ }^{102,103}$ Although enoxaparin causes more minor bleeding than UFH, the incidence of serious bleeding is not increased. Additional Activated Clotting Time (ACT)-activated IV boluses of UFH may be considered following initial UFH treatment.

Bleeding worsens the prognosis of patients with ACS. ${ }^{104}$ Fondaparinux ( $2.5 \mathrm{mg}$ sc daily) and bivalirudin $\left(0.1 \mathrm{mg} \mathrm{kg}^{-1}\right.$ iv followed by a $0.25 \mathrm{mg} \mathrm{kg}^{-1}$ infusion) cause less bleeding than UFH. ${ }^{105-107}$ Fondaparinux is recommended as having the most favourable efficacy-safety profile regardless of the management strategy. Since catheter thrombi were observed in patients undergoing PCI additional UFH during PCI is necessary. ${ }^{105}$

Enoxaparin or UFH are recommended when fondaparinux is not available. In the trials on patients presenting with non-STEMI-ACS, $\mathrm{UFH}$, fondaparinux, enoxaparin and bivalirudin were given only after hospital admission; it therefore may be invalid to extrapolate the results to the pre-hospital or ED setting.

Because of the reduced risk of bleeding, fondaparinux may be the preferred anticoagulant. Because enoxaparin and fondaparinux may accumulate in patients with renal impairment, dosing must be adjusted. For patients with a planned invasive approach, bivalirudin and enoxaparin are reasonable alternatives to UFH. The bleeding risk may be increased by switching between UFH and enoxaparin. ${ }^{108}$ Consider stopping anticoagulation after PCI unless otherwise indicated.

\section{Antithrombins in STEMI}

Antithrombins for patients to be treated with fibrinolysis.

Enoxaparin-UFH. It is reasonable to give UFH for patients treated with pre-hospital fibrinolysis for STEMI.

Several randomised studies of patients with STEMI undergoing fibrinolysis, however, have shown that additional treatment with enoxaparin instead of UFH resulted in better clinical outcomes (irrespective of the fibrinolytic used) but a slightly increased bleeding rate in elderly ( $\geq 75$ years) and low weight patients (BW $<60 \mathrm{~kg}$ ). ${ }^{109}$ Reduced doses of enoxaparin in elderly and low weight patients maintained the improved outcome while reducing the bleeding rate. ${ }^{110}$

Dosing of enoxaparin: in patients $<75$ years, give an initial bolus of $30 \mathrm{mg}$ IV followed by $1 \mathrm{mg} \mathrm{kg}^{-1}$ SC every $12 \mathrm{~h}$ (first SC dose shortly after the IV bolus). Treat patients $\geq 75$ years with $0.75 \mathrm{mg} \mathrm{kg}^{-1}$ SC every $12 \mathrm{~h}$ without an initial IV dose. Patients with known impaired renal function (creatinine clearance $<30 \mathrm{ml}^{-1} \mathrm{~min}^{-1}$ ) may be given $1 \mathrm{mg} \mathrm{kg}^{-1}$ enoxaparin SC once daily or may be treated with UFH. There are insufficient data to recommend other LMWH.

Fondaparinux. Several studies show superiority or neutral outcome when fondaparinux was compared with UFH as an adjunct for fibrinolysis in STEMI patients. ${ }^{105}$ Fondaparinux (initially $2.5 \mathrm{mg}$ SC followed by $2.5 \mathrm{mg}$ SC daily) may be considered specifically with non-fibrin-specific fibrinolytics (i.e. streptokinase) in patients with a plasma creatinine concentration $<3 \mathrm{mg} \mathrm{dl}^{-1}\left(250\right.$ micromol $\left.^{-1}\right)$. In case of planned PPCI, enoxaparin or UFH are preferred.

Bivalirudin. There are insufficient data to recommend bivalirudin instead of UFH or enoxaparin in STEMI patients to be treated with fibrinolysis. Since switching the anticoagulants may increase bleeding risk, the initial agent should be maintained, with the exception of fondaparinux, where additional UFH is necessary if an additional invasive procedure is planned. ${ }^{108}$

Anti-thrombins for STEMI patients to be treated with primary PCI $(P P C I)$. An injectable anticoagulant must be used in primary $\mathrm{PCI}$ for STEMI. After publication of the ERC 2010 Guidelines, studies have been performed comparing different antithrombin treatments with pre-hospital initiation for patients with STEMI and planned PPCI. ${ }^{98,99,111}$ With exemption of UFH (F), however, there is still a paucity of studies comparing the efficacy of pre-hospital with in-hospital initiation of treatment with the same anticoagulant i.e. the role of earlier start of therapy. Therefore treatment recommendations for these settings have to be extrapolated mainly from in-hospital investigations without proof of advantage of prehospital initiation of therapy, until more specific study results are available.

UFH. In one observational study pre-hospital injection of $500 \mathrm{mg}$ aspirin together with $>5000$ IU UFH led to a significantly higher rate of TIMI flow 2 and 3 and TIMI flow 3 at initial angiography. ${ }^{112}$ There was, however, no improvement in infarct size or 30 day mortality.

Enoxaparin. In one larger randomised study enoxaparin was compared with UFH in planned PPCI for STEMI. In $71 \%$ of patients anticoagulants were started in the ambulance. ${ }^{99}$ The study revealed no difference in the primary combined endpoint of death, procedure failure or major bleeding, but reductions in several secondary combined endpoints such as death, recurrent ACS and urgent revascularisation. Several registries and smaller studies also documented favourable or neutral outcome when enoxaparin was compared with UFH for PPCI (with broad use of thienopyridines and/or Gp IIB/IIIA receptor blockers). ${ }^{113}$ Therefore, enoxaparin is a safe and effective alternative to UFH and may be preferred over UFH also in the pre-hospital setting. There are insufficient data to recommend any LMWH other than enoxaparin for PPCI in STEMI. Switching from UFH to enoxaparin or vice versa may lead to an increased bleeding risk and therefore should be avoided. ${ }^{108}$ Dose adjustment of enoxaparin is necessary for patients with renal impairment.

Bivalirudin. Two large randomised studies documented less bleeding and a reduction in short and long term mortality when bivalirudin was compared with UFH plus Gp IIB/IIIA receptor blockers in patients with STEMI and planned PCI. ${ }^{114,115}$ Several other studies and case series showed also better or neutral results and less bleeding when bivalirudin was compared with UFH. Feasibility and safety of pre-hospital administration as well as reduced bleeding rates were shown in non-randomised studies when compared with historical controls. ${ }^{100,111}$ In newer trials testing bivalirudin against UFH with less extensive addition of GpIIb/IIIa receptor blockers, or a modified antiplatelet strategy differences in major bleedings were only minor, whereas results in ischaemic endpoints were neutral or even inferior with bivalirudin. ${ }^{116,117}$ A further study tested prehospital initiation of bivalirudin vs. UFH plus optional GpIIB/IIIa receptor antagonists, which was given in $69 \%$ of patients. Bleedings but not death were significantly reduced with bivalirudin; the rate of stent thromboses within the first $24 \mathrm{~h}$ after $\mathrm{PCI}$ was higher with bivalirudin as in other studies. ${ }^{98,118}$ Weighing reduced bleeding rates against higher rates of stent thrombosis bivalirudin may still be considered as an alternative to UFH in PPCI for STEMI.

Fondaparinux. When compared with UFH, fondaparinux resulted in similar clinical outcomes but less bleeding when used in the context of PPCI; ${ }^{105}$ however, thrombus formation on catheters required treatment with additional UFH. Therefore fondaparinux is not recommended for planned PPCI of STEMI.

\section{Reperfusion strategy in patients presenting with STEMI}

Reperfusion therapy in patients with STEMI is the most important advance in the treatment of myocardial infarction in the last 30 years. For patients presenting with STEMI within $12 \mathrm{~h}$ of symptom onset, reperfusion should be initiated as soon as possible using the most appropriate available strategy. ${ }^{119-122}$ Reperfusion may be achieved with fibrinolysis, with PPCI, or a combination of both. Efficacy of reperfusion therapy is profoundly dependent on the time 
Table 8.1

Contraindications for fibrinolysis

Absolute contraindications

Haemorrhagic stroke or stroke of unknown origin at any time

Ischaemic stroke in the preceding 6 months

Central nervous system damage or neoplasms

Recent major trauma/surgery/head injury (within the preceding 3 weeks)

Gastro-intestinal bleeding within the last month

Known bleeding disorder

Aortic dissection

Relative contraindications

Transient ischaemic attack in preceding 6 months

Oral anticoagulant therapy

Within 1 week post-partum

Non-compressible punctures

Traumatic resuscitation

Refractory hypertension (systolic blood pressure $>180 \mathrm{mmHg}$ )

Advanced liver disease

Infective endocarditis

Active peptic ulcer

According to the guidelines of the European Society of Cardiology

interval from symptom onset to reperfusion. Fibrinolysis is effective specifically in the first 2 to $3 \mathrm{~h}$ after symptom onset; $\mathrm{PPCI}$ is less time sensitive.

\section{Fibrinolysis}

A meta-analysis of 3 RCTs including 531 patients showed benefit of prehospital versus inhospital fibrinolysis in terms of survival to hospital discharge without evidence of additional harm in terms of major or intracranial bleeding. ${ }^{123-125}$ An effective and safe system for out-of-hospital fibrinolytic therapy requires adequate facilities for the diagnosis and treatment of STEMI and its complications. Fibrinolytic therapy can be given safely by trained paramedics, nurses or physicians using an established protocol, comprehensive training programs, and quality assurance programs with medical oversight. ${ }^{126}$ Ideally, there should be a capability of communicating with experienced hospital doctors. (e.g. emergency physicians or cardiologists). The real advantage of prehospital fibrinolysis is where there are long transport times, i.e. $>30-60 \mathrm{~min}$. The RCTs that showed benefit with pre-hospital fibrinolysis were conducted in healthcare settings with a mean difference in time between pre-hospital treatment and in hospital treatment of 33-52 min. Additionally, transport times to hospital were a mean of 38-60 min. As the transport time shortens, any expected advantage is lost. Thus, giving fibrinolytics out-of-hospital to patients with STEMI or signs and symptoms of an ACS with presumed new LBBB is beneficial. The efficacy is greatest early after onset of symptoms. Patients with symptoms of ACS and ECG evidence of STEMI (or presumably new LBBB or true posterior infarction) presenting directly to the ED should be given fibrinolytic therapy as soon as possible unless there is timely access to PPCI.

\section{Risks of fibrinolytic therapy}

Healthcare professionals who give fibrinolytic therapy must be aware of its contraindications (Table 8.1) and risks. Patients with large AMIs (e.g. indicated by extensive ECG changes) are likely to gain most from fibrinolytic therapy. Benefits of fibrinolytic therapy are less impressive in inferior wall infarctions than in anterior infarctions. Older patients have an absolute higher risk of death, but the absolute benefit of fibrinolytic therapy is similar to that of younger patients. Patients over 75 years have an increased risk of intracranial bleeding from fibrinolysis; thus, the absolute benefit of fibrinolysis is reduced by this complication. The risk of intracranial bleeding is increased in patients with a systolic blood pressure of over $180 \mathrm{mmHg}$; this degree of hypertension is a relative contraindication to fibrinolytic therapy. The risk of intracranial bleeding is also dependent on the chosen fibrinolytic, antithrombin and antiplatelet therapy. An alternative, while using enoxaparin, is halving the dose for tenecteplase in patients $>75$ years, which reduces the rate of intracranial bleeding without loss of efficacy. ${ }^{127,128}$

\section{Primary percutaneous intervention}

Coronary angioplasty with or without stent placement has become the first-line treatment for patients with STEMI. PPCI performed with a limited delay to first balloon inflation after first medical contact, at a high-volume centre, by an experienced operator who maintains an appropriate expert status, is the preferred treatment as it improves morbidity and mortality as compared with immediate fibrinolysis. ${ }^{129}$

\section{Fibrinolysis vs primary $P C I$}

Primary PCI has been limited by access to catheter laboratory facilities, appropriately skilled clinicians and delay to first balloon inflation. Fibrinolysis therapy is a widely available reperfusion strategy. Both treatment strategies are well established and have been the subject of large randomised multicentre trials over the last decades. Time from onset of symptoms and PPCI related delay (diagnosis to balloon interval minus the diagnosis to needle interval) are key in selecting the most appropriate revascularisation strategy.

Fibrinolytic therapy is most effective in patients presenting within 2-3 h from onset of ischaemic symptoms. It compares favourably with PPCI when started within $2 \mathrm{~h}$ from symptom onset and is combined with rescue or delayed $\mathrm{PCI} .{ }^{40,130,131}$ In the randomised studies comparing PPCI with fibrinolytic therapy, the typical delay from decision to the beginning of treatment with either PPCI or fibrinolytic therapy was less than $60 \mathrm{~min}$. In registries that reflect standard practice more realistically the acceptable PPCI-related delay (i.e. the diagnosis to balloon interval minus the diagnosis to needle interval) to maintain the superiority of PPCI over fibrinolysis varied considerably between 45 and $>180 \mathrm{~min}$ depending on the patients' conditions (i.e. age, localisation of infarction, and duration of symptoms). In STEMI registries, system delays to PCI may exceed $120 \mathrm{~min}$ in as many as $58 \%$ of patients with STEMI. ${ }^{132}$ Thus continuous monitoring of system performance is needed to assure optimal performance and outcomes for patients with STEMI.

In early presenters, patients of younger age and large anterior infarctions, PPCI related delays of $60 \mathrm{~min}$ may be unacceptable while in late presenters ( $>3 \mathrm{~h}$ from the onset of symptoms) PPCI related delays of up to 120 min may be acceptable. ${ }^{133}$

The presence of certain comorbidities such as previous CABG, diabetes and renal failure are additional factors to be considered for the selection of the most appropriate therapy. ${ }^{134}$

Time delay to PPCI may be significantly shortened by improving the systems of care ${ }^{135,136}$ :

- A pre-hospital ECG should be acquired as soon as possible and interpreted for the diagnosis of STEMI. This can reduce mortality in both patients planned for PPCI and fibrinolytic therapy.

- STEMI recognition may be accomplished by ECG transmission or onsite interpretation by physicians, or highly trained nurses or paramedics, with or without the aid of computer ECG interpretation.

- When PPCI is the planned strategy, pre-hospital activation of catheterisation laboratory for PPCI will contribute to a mortality benefit. ${ }^{40}$ 
Additional elements for an effective system of care include:

- Requiring the catheterisation laboratory to be ready within 20 min available 24/7.

- Providing real-time data feedback on the real time course from symptom onset to PCI.

For those patients with a contraindication to fibrinolysis, PCI should still be pursued despite the delay, rather than not providing reperfusion therapy at all. For those STEMI patients presenting in shock, primary PCI (or coronary artery bypass surgery) is the preferred reperfusion treatment. Fibrinolysis should only be considered if there is a substantial delay to PCI.

\section{Triage and inter-facility transfer for primary PCI}

The majority of patients with an ongoing STEMI will be first diagnosed either in the pre-hospital environment or in the setting of the ED of a non-PCI capable hospital. Therefore decisions have to be made as for the most appropriate strategy for revascularisation.

In the pre-hospital setting there is evidence suggesting that although pre-hospital fibrinolysis is not inferior to immediate transfer for primary PPCI in terms of mortality, it is associated with increased risk for intracranial haemorrhage. When PCI can be performed within a time limit of 60-90 min, then direct triage and transport for $\mathrm{PCI}$ is preferred to pre-hospital fibrinolysis. 40,127,137-139

When the patient with STEMI first appears in the emergency department of a non PCI hospital, data from 8 RCTs ${ }^{140-147}$ enrolling 3119 patients indicate that immediate transfer for $\mathrm{PPCI}$ is superior to local fibrinolytic therapy and transfer only for rescue PCI in terms of mortality, reinfarction and stroke without evidence for additional harm. Therefore, for adult patients presenting with STEMI in the ED of a non-PCI capable hospital emergent transfer without fibrinolysis to a PCI centre should be considered provided that PPCI can be performed within acceptable time delays.

It is less clear whether immediate fibrinolytic therapy (in- or out-of-hospital) or transfer for PPCI is superior for younger patients presenting with anterior infarction and within a short duration of $<2-3 \mathrm{~h} .{ }^{133}$ Transfer of STEMI patients for PPCI is reasonable for those presenting more than $3 \mathrm{~h}$ but less than $12 \mathrm{~h}$ after the onset of symptoms, provided that the transfer can be achieved rapidly.

\section{Combination of fibrinolysis and percutaneous coronary intervention}

Fibrinolysis and PCI may be used in a variety of combinations to restore and maintain coronary blood flow and myocardial perfusion. There are several ways in which the two therapies can be combined. There is some lack of uniformity in the nomenclature used to describe PCI in these regimens. Facilitated PCI is used to describe PCI performed immediately after fibrinolysis, a pharmacoinvasive strategy refers to $\mathrm{PCI}$ performed routinely 3 to $24 \mathrm{~h}$ after fibrinolysis, and rescue $\mathrm{PCI}$ is defined as PCI performed for a failed reperfusion (as evidenced by $<50 \%$ resolution of ST segment elevation at 60 to $90 \mathrm{~min}$ after completion of fibrinolytic treatment). These strategies are distinct from a routine PCI approach where the angiography and intervention is performed several days after successful fibrinolysis.

Routine immediate angiography post fibrinolytic therapy is associated with increased intracranial haemorrhage (ICH) and major bleeding without offering any benefit in terms of mortality or reinfarction. ${ }^{148-152}$

It is reasonable to perform angiography and PCI when necessary in patients with failed fibrinolysis according to clinical signs and/or insufficient ST-segment resolution. ${ }^{153}$
In case of clinically successful fibrinolysis (evidenced by clinical signs and ST-segment resolution $>50 \%$ ), angiography delayed by several hours after fibrinolysis (the pharmaco-invasive approach) has been shown to improve outcome. This strategy includes early transfer for angiography and PCI if necessary after fibrinolytic treatment.

Analysis of data form seven RCTs ${ }^{138,146,154-158}$ enrolling 2355 patients show benefit in terms of less reinfarctions in immediate routine transfer for angiography at 3-6h (or up to $24 \mathrm{~h}$ ) in first $24 \mathrm{~h}$ after ED fibrinolysis versus only transfer for rescue $\mathrm{PCI}$ after in hospital fibrinolysis (OR 0.57; 95\% CI 0.38-0.85). There was no evidence of benefit in terms of short term and 1 year mortality or for additional harm in terms of major haemorrhage or intracranial bleeding.

Data from two RCTs ${ }^{138,159}$ and one non $\mathrm{RCT}^{160}$ indicate no benefit from transfer to immediate $\mathrm{PCI}$ in comparison to fibrinolytic therapy followed by routine transfer for PCI 3 to $24 \mathrm{~h}$ later. Therefore in case PPCI cannot be achieved in due time, onsite fibrinolysis and transfer for angiography 3 to $24 \mathrm{~h}$ later is a reasonable alternative.

\section{Special situations}

\section{Cardiogenic shock}

Acute coronary syndrome (ACS) is the most common cause of cardiogenic shock, mainly through a large zone of myocardial ischaemia or a mechanical complication of myocardial infarction. Although uncommon, the short-term mortality of cardiogenic shock is up to $40 \%{ }^{161}$ contrasting with a good quality of life in patients discharged alive. An early invasive strategy (i.e. primary $\mathrm{PCI}, \mathrm{PCI}$ early after fibrinolysis) is indicated for those patients who are suitable for revascularisation. ${ }^{162}$ Observational studies suggest that this strategy could be also beneficial in elderly patients (over 75 years). Even if commonly used in clinical practice, there is no evidence supporting the use of IABP in cardiogenic shock. ${ }^{161}$

Suspect right ventricular infarction in patients with inferior infarction, clinical shock and clear lung fields. ST segment elevation $\geq 0.1 \mathrm{mV}$ in lead V4R is a useful indicator of right ventricular infarction. These patients have an in-hospital mortality of up to $30 \%$ and many benefit greatly from reperfusion therapy. Avoid nitrates and other vasodilators, and treat hypotension with intravenous fluids.

\section{Reperfusion after successful CPR}

As it is often accompanied by an acute coronary artery occlusion or by a high degree stenosis, acute coronary syndrome (ACS) is a frequent cause of out-of-hospital cardiac arrest (OHCA) In a recent meta-analysis, the prevalence of acute coronary artery lesion ranged from $59 \%$ to $71 \%$ in OHCA patients without an obvious non-cardiac cause. ${ }^{163}$ Since the publication of the pioneering study, ${ }^{164}$ many observational studies have shown that emergent cardiac catheter laboratory evaluation, including early percutaneous coronary intervention $(\mathrm{PCI})$, is feasible in patients with return of spontaneous circulation (ROSC) after cardiac arrest. ${ }^{165}$ The invasive management (i.e. early coronary angiography (CAG) followed by immediate PCI if deemed necessary) of this patient group, particularly patients after prolonged resuscitation and having nonspecific ECG changes, has been controversial due to the lack of specific evidence and significant implications on resource utilization (including transfer of patients to PCI centres).

PCI following ROSC with ST-elevation. The highest prevalence of acute coronary lesion is observed in patients with ST segment elevation (STE) or left bundle branch block (LBBB) on post-ROSC electrocardiogram (ECG). There is no randomised study but as many observational studies reported a benefit regarding survival and neurological outcome, it is highly probable that this early invasive 
management is a strategy associated with a clinically relevant benefit in patients with ST segment elevation. A recent meta-analysis indicates that early angiography is associated with reduction of hospital mortality [OR 0.35 (0.31 to 0.41)] and increased neurologically favourable survival [OR 2.54 (2.17 to 2.99)].$^{40}$ However patients that underwent early angiography were highly selected populations with higher prevalence of male gender, VF, witnessed arrest, therapeutic hypothermia and more intense LV support. Diabetes mellitus, renal and heart failure were less prevalent in these patients.

Based on the available data, emergent cardiac catheterisation lab evaluation (and immediate $\mathrm{PCI}$ if required) should be performed in selected adult patients with ROSC after OHCA of suspected cardiac origin with ST segment elevation on ECG. ${ }^{166}$

Observational studies also indicate that optimal outcomes after OHCA are achieved with a combination of targeted temperature management and $\mathrm{PCI}$, which can be combined in a standardised post-cardiac-arrest protocol as part of an overall strategy to improve neurologically intact survival in this patient group.

PCI following ROSC without ST-elevation. In contrast to the usual presentation of ACS in non cardiac arrest patients, recommended tools to assess coronary ischaemia are less accurate in this setting. Both sensitivity and specificity of clinical data, ECG and biomarkers to predict an acute coronary artery occlusion as the cause of OHCA are debatable. ${ }^{167}$ In particular several large observational series showed that absence of STE may also be associated with ACS in patients with ROSC following OHCA. ${ }^{168}$ In these non-STE patients, data are conflicting regarding the potential benefit of an emergent cardiac catheterisation lab evaluation, all coming from observational studies, ${ }^{169,170}$ or subgroup analysis. ${ }^{171}$ It is reasonable to discuss an emergent cardiac catheterisation lab evaluation after ROSC in patients with the highest risk of coronary cause of CA. A variety of factors such as patient age, duration of CPR, haemodynamic instability, presenting cardiac rhythm, neurologic status upon hospital arrival, and perceived likelihood of cardiac aetiology can influence the decision to undertake the intervention. A recent consensus statement from the European Association for Percutaneous Cardiovascular Interventions (EAPCI) has emphasised that in OHCA patients, cardiac catheterisation should be performed immediately in the presence of ST-elevation and considered as soon as possible (less than two hours) in other patients in the absence of an obvious non-coronary cause, particularly if they are haemodynamically unstable. ${ }^{172}$ In patients who present in a non-PCI centre transfer for angiography and PPCI if indicated should be considered on an individual basis, weighing the expected benefits from early angiography against the risks from patient transport.

\section{Preventive interventions}

Preventive interventions in patients presenting with ACS should be initiated early after hospital admission and should be continued if already in place. Preventive measures improve prognosis by reducing the number of major adverse cardiac events. Prevention with drugs encompasses beta-blockers, angiotensin converting enzyme (ACE) inhibitors/angiotensin receptor blockers (ARB) and statins, as well as basic treatment with ASA and, if indicated, thienopyridines.

\section{Beta-blockers}

Several studies, undertaken mainly in the pre-reperfusion era, indicate a decreased mortality, incidence of reinfarction and cardiac rupture as well as a lower incidence of ventricular fibrillation and supraventricular arrhythmia in patients treated early with a beta-blocker. ${ }^{173}$ Beta-blocker studies are very heterogeneous with respect to time of start of treatment. There is paucity of data on administration in the pre-hospital or ED settings. Moreover, studies indicate an increased risk of cardiogenic shock with IV beta-blockers in patients with STEMI, even if the rate of severe tachyarrhythmia is reduced by beta-blockade. ${ }^{174}$ There is no evidence to support routine intravenous beta-blockers in the pre-hospital or initial ED settings. Early IV use of beta-blockers is contraindicated in patients with clinical signs of hypotension or congestive heart failure. It may be indicated in special situations such as severe hypertension or tachyarrhythmias in the absence of contraindications. It is reasonable to start oral beta-blockers at low doses only after the patient is stabilised.

\section{Other anti-arrhythmics}

Apart from beta-blockers, there is no evidence to support the use of anti-arrhythmic prophylaxis after ACS. Ventricular fibrillation (VF) accounts for most of the early deaths from ACS; the incidence of VF is highest in the first hours after onset of symptoms. This explains why numerous studies have been performed with the aim of demonstrating the prophylactic effect of antiarrhythmic therapy. ${ }^{175}$ The effects of antiarrhythmic drugs (lidocaine, magnesium, disopyramide, mexiletine, verapamil, sotalol, tocainamide) given prophylactically to patients with ACS have been studied. Prophylaxis with lidocaine reduces the incidence of VF but may increase mortality. ${ }^{176}$ Routine treatment with magnesium in patients with AMI does not reduce mortality. Arrhythmia prophylaxis using disopyramide, mexiletine, verapamil, or other anti-arrhythmics given within the first hours of an ACS does not improve mortality. Therefore prophylactic anti-arrhythmics are not recommended.

\section{Angiotensin-converting enzyme inhibitors, angiotensin receptor blockers}

Oral ACE inhibitors reduce mortality when given to patients with AMI with or without early reperfusion therapy. The beneficial effects are most pronounced in patients presenting with anterior infarction, pulmonary congestion or left ventricular ejection fraction $<40 \%$. Do not give ACE inhibitors if the systolic blood pressure is less than $100 \mathrm{mmHg}$ on admission or if there is a known contraindication to these drugs. A trend towards higher mortality has been documented if an intravenous ACE inhibitor is started within the first $24 \mathrm{~h}$ after onset of symptoms. This therapy is safe, well tolerated and associated with a small but significant reduction in 30-day mortality. ${ }^{177}$ Therefore, give an oral ACE inhibitor within $24 \mathrm{~h}$ after symptom onset in patients with AMI regardless of whether early reperfusion therapy is planned, particularly in those patients with anterior infarction, pulmonary congestion or a left ventricular ejection fraction below $40 \%$. Do not give intravenous ACE inhibitors within $24 \mathrm{~h}$ of onset of symptoms. ${ }^{178,179}$ Give an angiotensin receptor blocker (ARB) to patients intolerant of ACE inhibitors. ${ }^{180}$

\section{Lipid-lowering therapy}

Statins reduce the incidence of major adverse cardiovascular events when given early within the first days after onset an ACS. ${ }^{181,182}$ Consider starting statin therapy in all patients within $24 \mathrm{~h}$ of onset of symptoms of ACS unless contraindicated. If patients are already receiving statin therapy, do not stop it. ${ }^{183}$

\section{Collaborator}

Nicolas Danchin, Department of Cardiology, Hôpital Européen Georges Pompidou, Paris, France. 


\section{Conflicts of interest}

Nikolaos Nikolaou Research grant Fourier trial-AMGEN Alain Cariou Speakers honorarium BARD-France

Farzin Beygui $\quad$ Speakers honorarium Astra Zeneca, Lilly, Daichi-Sankyo

\section{References}

1. Perk J, De Backer G, Gohlke H, et al. European Guidelines on cardiovascular disease prevention in clinical practice (version 2012). The Fifth Joint Task Force of the European Society of Cardiology and Other Societies on Cardiovascular Disease Prevention in Clinical Practice (constituted by representatives of nine societies and by invited experts). Eur Heart J 2012;33:1635-701.

2. Goodman SG, Huang W, Yan AT, et al. The expanded global registry of acute coronary events: baseline characteristics, management practices, and hospital outcomes of patients with acute coronary syndromes. Am Heart J 2009;158:193.e1-5.

3. Dudas K, Lappas G, Stewart S, Rosengren A. Trends in out-of-hospital deaths due to coronary heart disease in Sweden (1991 to 2006). Circulation 2011;123:46-52

4. Thygesen K, Alpert JS, Jaffe AS, et al. Third universal definition of myocardial infarction. J Am Coll Cardiol 2012;60:1581-98.

5. Task Force on the management of ST-segment elevation acute myocardial infarction of the European Society of Cardiology, Steg PG, James SK, et al. ESC Guidelines for the management of acute myocardial infarction in patients presenting with ST-segment, elevation. Eur Heart J 2012;33:2569-619.

6. Roffi M, Patrono C, Collet JP, et al. ESC Guidelines for the management of acute coronary syndromes in patients presenting without persistent STsegment elevation: Task Force for the Management of Acute Coronary Syndromes in Patients Presenting without Persistent ST-Segment Elevation of the European Society of Cardiology (ESC). Eur Heart J 2015, http://dx.doi.org/10.1093/eurheartj/ehv320.

7. Henrikson CA, Howell EE, Bush DE, et al. Chest pain relief by nitroglycerin does not predict active coronary artery disease. Ann Intern Med 2003;139:979-86.

8. American College of Emergency P, Society for Cardiovascular A, Interventions, et al. 2013 ACCF/AHA guideline for the management of ST-elevation myocardial infarction: a report of the American College of Cardiology Foundation/American Heart Association Task Force on Practice, Guidelines. J Am Coll Cardiol 2013;61:e78-140.

9. Amsterdam EA, Wenger NK, Brindis RG, et al. 2014 AHA/ACC guideline for the management of patients with non-ST-elevation acute coronary syndromes: executive summary: a report of the American College of Cardiology/American Heart Association Task Force on Practice Guidelines. Circulation 2014;130:2354-94.

10. Amsterdam EA, Wenger NK, Brindis RG, et al. 2014 AHA/ACC Guideline for the Management of Patients with Non-ST-Elevation Acute Coronary Syndromes: a report of the American College of Cardiology/American Heart Association Task Force on Practice Guidelines. J Am Coll Cardiol 2014;64:e139-228.

11. Canto JG, Rogers WJ, Bowlby LJ, French WJ, Pearce DJ, Weaver WD. The prehospital electrocardiogram in acute myocardial infarction: is its full potential being realized? National Registry of Myocardial Infarction 2 Investigators. J Am Coll Cardiol 1997;29:498-505.

12. Terkelsen CJ, Lassen JF, Norgaard BL, et al. Reduction of treatment delay in patients with ST-elevation myocardial infarction: impact of pre-hospital diagnosis and direct referral to primary percutanous coronary intervention. Eur Heart J 2005;26:770-7.

13. Carstensen S, Nelson GC, Hansen PS, et al. Field triage to primary angioplasty combined with emergency department bypass reduces treatment delays and is associated with improved outcome. Eur Heart J 2007;28: 2313-9.

14. Brown JP, Mahmud E, Dunford JV, Ben-Yehuda O. Effect of prehospital 12-lead electrocardiogram on activation of the cardiac catheterization laboratory and door-to-balloon time in ST-segment elevation acute myocardial infarction. Am J Cardiol 2008;101:158-61.

15. Martinoni A, De Servi S, Boschetti E, et al. Importance and limits of prehospital electrocardiogram in patients with ST elevation myocardial infarction undergoing percutaneous coronary angioplasty. Eur J Cardiovasc Prev Rehabil 2011;18:526-32 (official journal of the European Society of Cardiology, Working Groups on Epidemiology \& Prevention and Cardiac Rehabilitation and Exercise Physiology).

16. Sorensen JT, Terkelsen CJ, Norgaard BL, et al. Urban and rural implementation of pre-hospital diagnosis and direct referral for primary percutaneous coronary intervention in patients with acute ST-elevation myocardial infarction. Eur Heart J 2011;32:430-6.

17. Chan AW, Kornder J, Elliott H, et al. Improved survival associated with prehospital triage strategy in a large regional ST-segment elevation myocardial infarction program. JACC Cardiovasc Interv 2012;5:1239-46.

18. Quinn T, Johnsen S, Gale CP, et al. Effects of prehospital 12-lead ECG on processes of care and mortality in acute coronary syndrome: a linked cohort study from the myocardial ischaemia national audit project. Heart 2014;100: 944-50.

19. Ong ME, Wong AS, Seet CM, et al. Nationwide improvement of doorto-balloon times in patients with acute ST-segment elevation myocardial infarction requiring primary percutaneous coronary intervention with out-of hospital 12-lead ECG recording and transmission. Ann Emerg Med 2013;61: 339-47.

20. Swor R, Hegerberg S, McHugh-McNally A, Goldstein M, McEachin CC. Prehospital 12-lead ECG: efficacy or effectiveness? Prehosp Emerg Care 2006;10:374-7 (official journal of the National Association of EMS Physicians and the National Association of State EMS Directors).

21. Masoudi FA, Magid DJ, Vinson DR, et al. Implications of the failure to identify high-risk electrocardiogram findings for the quality of care of patients with acute myocardial infarction: results of the Emergency Department Quality in Myocardial Infarction (EDQMI) study. Circulation 2006;114:1565-71.

22. Kudenchuk PJ, Ho MT, Weaver WD, et al. Accuracy of computer-interpreted electrocardiography in selecting patients for thrombolytic therapy MITI project investigators. J Am Coll Cardiol 1991;17:1486-91.

23. Dhruva VN, Abdelhadi SI, Anis A, et al. ST-Segment Analysis Using Wireless Technology in Acute Myocardial Infarction (STAT-MI) trial. J Am Coll Cardiol 2007;50:509-13.

24. Bhalla MC, Mencl F, Gist MA, Wilber S, Zalewski J. Prehospital electrocardiographic computer identification of ST-segment elevation myocardial infarction. Prehosp Emerg Care 2013;17:211-6 (official journal of the National Association of EMS Physicians and the National Association of State EMS Directors).

25. Clark EN, Sejersten M, Clemmensen P, Macfarlane PW. Automated electrocardiogram interpretation programs versus cardiologists' triage decision making based on teletransmitted data in patients with suspected acute coronary syndrome. Am J Cardiol 2010;106:1696-702.

26. de Champlain F, Boothroyd LJ, Vadeboncoeur A, et al. Computerized interpretation of the prehospital electrocardiogram: predictive value for ST segment elevation myocardial infarction and impact on on-scene time. CJEM 2014;16:94-105.

27. Squire BT, Tamayo-Sarver JH, Rashi P, Koenig W, Niemann JT. Effect of prehospital cardiac catheterization lab activation on door-to-balloon time, mortality, and false-positive activation. Prehosp Emerg Care 2014;18:1-8 (official journal of the National Association of EMS Physicians and the National Association of State EMS Directors).

28. Youngquist ST, Shah AP, Niemann JT, Kaji AH, French WJ. A comparison of door-to-balloon times and false-positive activations between emergency department and out-of-hospital activation of the coronary catheterization team. Acad Emerg Med 2008;15:784-7 (official journal of the Society for Academic Emergency Medicine)

29. van't Hof AW, Rasoul S, van de Wetering H, et al. Feasibility and benefit of prehospital diagnosis, triage, and therapy by paramedics only in patients who are candidates for primary angioplasty for acute myocardial infarction. Am Heart J 2006;151:1255.e1-5.

30. Layfield C, Rose J, Alford A, et al. Effectiveness of practices for improving the diagnostic accuracy of non ST elevation myocardial infarction in the emergency department: a laboratory medicine best practices systematic review. Clin Biochem 2015;48:204-12

31. Hamm CW, Bassand JP, Agewall S, et al. ESC Guidelines for the management of acute coronary syndromes in patients presenting without persistent ST-segment elevation: the Task Force for the management of acute coronary syndromes (ACS) in patients presenting without persistent STsegment elevation of the European Society of Cardiology (ESC). Eur Heart J 2011;32:2999-3054.

32. Keller T, Zeller T, Peetz D, et al. Sensitive troponin I assay in early diagnosis of acute myocardial infarction. N Engl J Med 2009;361:868-77.

33. Pope JH, Aufderheide TP, Ruthazer R, et al. Missed diagnoses of acute cardiac ischemia in the emergency department. N Engl J Med 2000;342:1163-70.

34. Collinson PO, Premachandram S, Hashemi K. Prospective audit of incidence of prognostically important myocardial damage in patients discharged from emergency department. BMJ 2000;320:1702-5.

35. Aldous SJ, Richards M, Cullen L, Troughton R, Than M. A 2-h thrombolysis in myocardial infarction score outperforms other risk stratification tools in patients presenting with possible acute coronary syndromes: comparison of chest pain risk stratification tools. Am Heart J 2012;164:516-23.

36. Than M, Cullen L, Reid CM, et al. A 2-h diagnostic protocol to assess patients with chest pain symptoms in the Asia-Pacific region (ASPECT): a prospective observational validation study. Lancet 2011;377:1077-84.

37. Than M, Cullen L, Aldous S, et al. 2-h accelerated diagnostic protocol to assess patients with chest pain symptoms using contemporary troponins as the only biomarker: the ADAPT trial. J Am Coll Cardiol 2012;59:2091-8.

38. Reichlin T, Schindler C, Drexler B, et al. One-hour rule-out and rule-in of acute myocardial infarction using high-sensitivity cardiac troponin T. Arch Intern Med 2012:172:1211-8.

39. Meller B, Cullen L, Parsonage WA, et al. Accelerated diagnostic protocol using high-sensitivity cardiac troponin $\mathrm{T}$ in acute chest pain patients. Int J Cardiol 2015; $184: 208-15$

40. Nikolaou N, Welsford M, Beygui F, et al. Part 5: Acute coronary syndromes: 2015 International Consensus on Cardiopulmonary Resuscitation and Emergency Cardiovascular Care Science with Treatment Recommendations. Resuscitation 2015:95:e123-48.

41. Renaud B, Maison P, Ngako A, et al. Impact of point-of-care testing in the emergency department evaluation and treatment of patients with suspected acute coronary syndromes. Acad Emerg Med 2008;15:216-24 (official journal of the Society for Academic Emergency Medicine). 
42. Mitchell AM, Garvey JL, Kline JA. Multimarker panel to rule out acute coronary syndromes in low-risk patients. Acad Emerg Med 2006;13:803-6 (official journal of the Society for Academic Emergency Medicine)

43. Sorensen JT, Terkelsen CJ, Steengaard C, et al. Prehospital troponin T testing in the diagnosis and triage of patients with suspected acute myocardial infarction. Am J Cardiol 2011;107:1436-40.

44. Loewenstein D, Stake C, Cichon M. Assessment of using fingerstick blood sample with i-STAT point-of-care device for cardiac troponin I assay. Am J Emerg Med 2013;31:1236-9.

45. D'Ascenzo F, Biondi-Zoccai G, Moretti C, et al. TIMI, GRACE and alternative risk scores in Acute Coronary Syndromes: a meta-analysis of 40 derivation studies on 216,552 patients and of 42 validation studies on 31,625 patients. Contemp Clin Trials 2012;33:507-14.

46. Cullen L, Greenslade J, Hammett CJ, et al. Comparison of three risk stratification rules for predicting patients with acute coronary syndrome presenting to an Australian emergency department. Heart Lung Circ 2013;22:844-51.

47. Lin A, Devlin G, Lee M, Kerr AJ. Performance of the GRACE scores in a New Zealand acute coronary syndrome cohort. Heart 2014;100:1960-6.

48. Tymchak W, Armstrong PW, Westerhout CM, et al. Mode of hospital presentation in patients with non-ST-elevation myocardial infarction: implications for strategic management. Am Heart J 2011;162:436-43.

49. Fox KA, Fitzgerald G, Puymirat E, et al. Should patients with acute coronary disease be stratified for management according to their risk? Derivation, external validation and outcomes using the updated GRACE risk score. BMJ Open 2014:4:e004425.

50. Farkouh ME, Smars PA, Reeder GS, et al. A clinical trial of a chest-pain observation unit for patients with unstable angina Chest Pain Evaluation in the Emergency Room (CHEER) Investigators. N Engl J Med 1998;339:1882-8.

51. Hermann LK, Newman DH, Pleasant WA, et al. Yield of routine provocative cardiac testing among patients in an emergency department-based chest pain unit. JAMA Intern Med 2013;173:1128-33.

52. Ramakrishna G, Milavetz JJ, Zinsmeister AR, et al. Effect of exercise treadmill testing and stress imaging on the triage of patients with chest pain: CHEER substudy. Mayo Clin Proc 2005;80:322-9.

53. Goldstein JA, Gallagher MJ, O’Neill WW, Ross MA, O'Neil BJ, Raff GL. A randomized controlled trial of multi-slice coronary computed tomography for evaluation of acute chest pain. J Am Coll Cardiol 2007;49:863-71.

54. Forberg JL, Hilmersson CE, Carlsson M, et al. Negative predictive value and potential cost savings of acute nuclear myocardial perfusion imaging in low risk patients with suspected acute coronary syndrome: a prospective single blinded study. BMC Emerg Med 2009;9:12.

55. Nucifora G, Badano LP, Sarraf-Zadegan N, et al. Comparison of early dobutamine stress echocardiography and exercise electrocardiographic testing for management of patients presenting to the emergency department with chest pain. Am J Cardiol 2007; 100:1068-73.

56. Wei K. Utility contrast echocardiography in the emergency department. JACC Cardiovasc Imaging 2010;3:197-203.

57. Gaibazzi N, Squeri A, Reverberi C, et al. Contrast stress-echocardiography predicts cardiac events in patients with suspected acute coronary syndrome but nondiagnostic electrocardiogram and normal 12-h troponin. J Am Soc Echocardiogr 2011;24:1333-41.

58. Douglas PS, Khandheria B, Stainback RF, et al. ACCF/ASE/ACEP/ ASNC/SCAI/SCCT/SCMR 2007 appropriateness criteria for transthoracic and transesophageal echocardiography: a report of the American College of Cardiology Foundation Quality Strategic Directions Committee Appropriateness Criteria Working Group, American Society of Echocardiography, American College of Emergency Physicians, American Society of Nuclear Cardiology, Society for Cardiovascular Angiography and Interventions Society of Cardiovascular Computed Tomography, and the Society for Cardiovascular Magnetic Resonance endorsed by the American College of Chest Physicians and the Society of Critical Care Medicine. J Am Coll Cardiol 2007;50:187-204.

59. Hoffmann U, Bamberg F, Chae CU, et al. Coronary computed tomography angiography for early triage of patients with acute chest pain: the ROMICAT (Rule Out Myocardial Infarction using Computer Assisted Tomography) trial. J Am Coll Cardiol 2009;53:1642-50.

60. Hoffmann U, Nagurney JT, Moselewski F, et al. Coronary multidetector computed tomography in the assessment of patients with acute chest pain. Circulation 2006;114:2251-60.

61. Hollander JE, Chang AM, Shofer FS, McCusker CM, Baxt WG, Litt HI. Coronary computed tomographic angiography for rapid discharge of low-risk patients with potential acute coronary syndromes. Ann Emerg Med 2009:53:295-304.

62. Pundziute G, Schuijf JD, Jukema JW, et al. Prognostic value of multislice computed tomography coronary angiography in patients with known or suspected coronary artery disease. J Am Coll Cardiol 2007:49:62-70.

63. Rubinshtein R, Halon DA, Gaspar T, et al. Impact of 64-slice cardiac computed tomographic angiography on clinical decision-making in emergency department patients with chest pain of possible myocardial ischemic origin. Am J Cardiol 2007;100:1522-6.

64. Janne d'Othee B, Siebert U, Cury R, Jadvar H, Dunn EJ, Hoffmann U. A systematic review on diagnostic accuracy of CT-based detection of significant coronary artery disease. Eur J Radiol 2008:65:449-61.

65. Sirol M, Sanz J, Henry P, Rymer R, Leber A. Evaluation of 64-slice MDCT in the real world of cardiology: a comparison with conventional coronary angiography. Arch Cardiovasc Dis 2009;102:433-9.

66. Galperin-Aizenberg M, Cook TS, Hollander JE, Litt HI, Cardiac CT. Angiography in the emergency department. AJR Am J Roentgenol 2015;204:463-74.
67. Cury RC, Feuchtner GM, Batlle JC, et al. Triage of patients presenting with chest pain to the emergency department: implementation of coronary CT angiography in a large urban health care system. AJR Am J Roentgenol 2013:200:57-65

68. Gruettner J, Henzler T, Sueselbeck T, Fink C, Borggrefe M, Walter T. Clinical assessment of chest pain and guidelines for imaging. Eur J Radiol 2012;81:3663-8

69. Samad Z, Hakeem A, Mahmood SS, et al. A meta-analysis and systematic review of computed tomography angiography as a diagnostic triage tool for patients with chest pain presenting to the emergency department. J Nucl Cardiol 2012;19:364-76.

70. Werns SW. Are nitrates safe in patients who use sildenafil? Maybe. Crit Care Med 2007;35:1988-90.

71. O'Gara PT, Kushner FG, Ascheim DD, et al. 2013 ACCF/AHA guideline for the management of ST-elevation myocardial infarction: a report of the American College of Cardiology Foundation/American Heart Association Task Force on Practice Guidelines. Circulation 2013;127:e362-425.

72. Kearney PM, Baigent C, Godwin J, Halls H, Emberson JR, Patrono C. Do selective cyclo-oxygenase-2 inhibitors and traditional non-steroidal anti-inflammatory drugs increase the risk of atherothrombosis? Meta-analysis of randomised trials. BMJ 2006;332:1302-8.

73. Rawles JM, Kenmure AC. Controlled trial of oxygen in uncomplicated myocardial infarction. Br Med J 1976;1:1121-3.

74. Wijesinghe M, Perrin K, Ranchord A, Simmonds M, Weatherall M, Beasley R. Routine use of oxygen in the treatment of myocardial infarction: systematic review. Heart 2009;95:198-202.

75. Stub D, Smith K, Bernard S, et al. Air versus oxygen in ST-segment elevation myocardial infarction. Circulation 2015;131:2143-50.

76. Cabello JB, Burls A, Emparanza JI, Bayliss S, Quinn T. Oxygen therapy for acute myocardial infarction. Cochrane Database Syst Rev 2013;8:CD007160.

77. Nolan JP, Soar J, Cariou A, et al. European Resuscitation Council and European Society of Intensive Care Medicine Guidelines for Post-resuscitation Care 2015 Section 5 Post Resuscitation Care. Resuscitation 2015;95:201-21.

78. Freimark D, Matetzky S, Leor J, et al. Timing of aspirin administration as a determinant of survival of patients with acute myocardial infarction treated with thrombolysis. Am J Cardiol 2002:89:381-5.

79. Frilling B, Schiele R, Gitt AK, et al. Characterization and clinical course of patients not receiving aspirin for acute myocardial infarction: results from the MITRA and MIR studies. Am Heart J 2001;141:200-5.

80. O'Gara PT, Kushner FG, Ascheim DD, et al. 2013 ACCF/AHA guideline for the management of ST-elevation myocardial infarction: executive summary: a report of the American College of Cardiology Foundation/American Heart Association Task Force on Practice Guidelines. Circulation 2013:127:529-55.

81. Wiviott SD, Braunwald E, McCabe $\mathrm{CH}$, et al. Prasugrel versus clopidogrel in patients with acute coronary syndromes. N Engl J Med 2007;357:2001-15

82. Wallentin L, Becker RC, Budaj A, et al. Ticagrelor versus clopidogrel in patients with acute coronary syndromes. N Engl J Med 2009;361:1045-57.

83. Yusuf S, Zhao F, Mehta SR, Chrolavicius S, Tognoni G, Fox KK. Effects of clopidogrel in addition to aspirin in patients with acute coronary syndromes without ST-segment elevation. N Engl J Med 2001;345:494-502.

84. Montalescot G, Bolognese L, Dudek D, et al. Pretreatment with prasugrel in non-ST-segment elevation acute coronary syndromes. N Engl J Med 2013:369:999-1010.

85. Zeymer U. Oral antiplatelet therapy in acute coronary syndromes: recent developments. Cardiol Ther 2013;2:47-56.

86. Ducci K, Grotti S, Falsini G, et al. Comparison of pre-hospital $600 \mathrm{mg}$ or $900 \mathrm{mg}$ vs. peri-interventional $300 \mathrm{mg}$ clopidogrel in patients with ST-elevation myocardial infarction undergoing primary coronary angioplasty the Load \& Go randomized trial. Int J Cardiol 2013;168:4814-6.

87. Bellemain-Appaix A, O'Connor SA, Silvain J, et al. Association of clopidogre pretreatment with mortality, cardiovascular events, and major bleeding among patients undergoing percutaneous coronary intervention: a systematic review and meta-analysis. JAMA 2012;308:2507-16.

88. Sabatine MS, Cannon CP, Gibson CM, et al. Addition of clopidogrel to aspirin and fibrinolytic therapy for myocardial infarction with ST-segment elevation. N Engl J Med 2005;352:1179-89.

89. Chen ZM, Jiang LX, Chen YP, et al. Addition of clopidogrel to aspirin in 45,852 patients with acute myocardial infarction: randomised placebo-controlled trial. Lancet 2005;366:1607-21.

90. Verheugt FW, Montalescot G, Sabatine MS, et al. Prehospital fibrinolysis with dual antiplatelet therapy in ST-elevation acute myocardial infarction: a substudy of the randomized double blind CLARITY-TIMI 28 trial. J Thromb Thrombolysis 2007;23:173-9.

91. Montalescot G, Wiviott SD, Braunwald E, et al. Prasugrel compared with clopidogrel in patients undergoing percutaneous coronary intervention for STelevation myocardial infarction (TRITON-TIMI 38): double-blind, randomised controlled trial. Lancet 2009;373:723-31.

92. Montalescot G, van't Hof AW, Lapostolle F, et al. Prehospital ticagrelor in STsegment elevation myocardial infarction. N Engl J Med 2014;371:1016-27.

93. Boersma E, Harrington RA, Moliterno DJ, et al. Platelet glycoprotein IIb/IIIa inhibitors in acute coronary syndromes: a meta-analysis of all major randomised clinical trials. [erratum appears in Lancet 2002 Jun 15:359(9323): 2120]. Lancet 2002;359:189-98.

94. Keeley EC, Boura JA, Grines CL. Comparison of primary and facilitated percutaneous coronary interventions for ST-elevation myocardial infarction: quantitative review of randomised trials. Lancet 2006;367:579-88. 
95. ten Berg JM, van't Hof AW, Dill T, et al. Effect of early, pre-hospital initiation of high bolus dose tirofiban in patients with ST-segment elevation myocardial infarction on short- and long-term clinical outcome. J Am Coll Cardiol 2010;55:2446-55.

96. Bellandi GDEL, Huber FK, et al. Early glycoprotein IIb-IIIa inhibitors in primary angioplasty-abciximab long-term results (EGYPT-ALT) cooperation: individual patient's data meta-analysis. J Thromb Haemost: JTH 2011:9:2361-70.

97. Mehilli J, Kastrati A, Schulz S, et al. Abciximab in patients with acute STsegment-elevation myocardial infarction undergoing primary percutaneous coronary intervention after clopidogrel loading: a randomized double-blind trial. Circulation 2009;119:1933-40.

98. Steg PG, van’t Hof A, Hamm CW, et al. Bivalirudin started during emergency transport for primary PCI. N Engl J Med 2013;369:2207-17.

99. Montalescot G, Zeymer U, Silvain J, et al. Intravenous enoxaparin or unfractionated heparin in primary percutaneous coronary intervention for ST-elevation myocardial infarction: the international randomised open-label ATOLL trial. Lancet 2011;378:693-703.

100. Sejersten M, Nielsen SL, Engstrom T, Jorgensen E, Clemmensen P. Feasibility and safety of prehospital administration of bivalirudin in patients with ST-elevation myocardial infarction. Am J Cardiol 2009;103:1635-40.

101. Mega JL, Braunwald E, Wiviott SD, et al. Rivaroxaban in patients with a recent acute coronary syndrome. N Engl J Med 2012;366:9-19.

102. TIMI-11B Investigators, Antman EM, McCabe $\mathrm{CH}$, et al. Enoxaparin prevents death and cardiac ischemic events in unstable angina/non-Q-wave myocardial infarction results of the thrombolysis in myocardial infarction (TIMI) 11B trial. Circulation 1999;100:1593-601.

103. Cohen M, Demers C, Gurfinkel EP, et al. A comparison of low-molecular-weight heparin with unfractionated heparin for unstable coronary artery disease. Efficacy and Safety of Subcutaneous Enoxaparin in Non-Q-Wave Coronary Events Study Group. N Engl J Med 1997;337:447-52.

104. Moscucci M, Fox KA, Cannon CP, et al. Predictors of major bleeding in acute coronary syndromes: the Global Registry of Acute Coronary Events (GRACE). Eur Heart J 2003;24:1815-23.

105. Yusuf S, Mehta SR, Chrolavicius S, et al. Comparison of fondaparinux and enoxaparin in acute coronary syndromes. N Engl J Med 2006;354:1464-76.

106. Mehta SR, Boden WE, Eikelboom JW, et al. Antithrombotic therapy with fondaparinux in relation to interventional management strategy in patients with ST- and non-ST-segment elevation acute coronary syndromes: an individual patient-level combined analysis of the Fifth and Sixth Organization to Assess Strategies in Ischemic Syndromes (OASIS 5 and 6) randomized trials. Circulation 2008; 118:2038-46.

107. Stone GW, McLaurin BT, Cox DA, et al. Bivalirudin for patients with acute coronary syndromes. N Engl J Med 2006;355:2203-16.

108. Ferguson JJ, Califf RM, Antman EM, et al. Enoxaparin vs. unfractionated heparin in high-risk patients with non-ST-segment elevation acute coronary syndromes managed with an intended early invasive strategy: primary results of the SYNERGY randomized trial. JAMA 2004;292:45-54.

109. Wallentin L, Goldstein P, Armstrong PW, et al. Efficacy and safety of tenecteplase in combination with the low-molecular-weight heparin enoxaparin or unfractionated heparin in the prehospital setting: the Assessment of the Safety and Efficacy of a New Thrombolytic Regimen (ASSENT)-3 PLUS randomized trial in acute myocardial infarction. Circulation 2003;108: $135-42$.

110. Antman EM, Morrow DA, McCabe CH, et al. Enoxaparin versus unfractionated heparin with fibrinolysis for ST-elevation myocardial infarction. N Engl J Med 2006;354:1477-88.

111. Hirschl MM, Mayr H, Erhart F, et al. Prehospital treatment of patients with acute myocardial infarction with bivalirudin. Am J Emerg Med 2012;30:12-7.

112. Zijlstra F, Ernst N, De Boer M-J, et al. Influence of prehospital administration of aspirin and heparin on initial patency of the infarct-related artery in patients with acute ST elevation myocardial infarction. J Am Coll Cardiol 2002;39:1733-7.

113. Zeymer U, Gitt A, Zahn R, et al. Efficacy and safety of enoxaparin in combination with and without GP IIb/IIIa inhibitors in unselected patients with ST segment elevation myocardial infarction treated with primary percutaneous coronary intervention. EuroIntervention 2009;4:524-8

114. Stone GW, Witzenbichler B, Guagliumi G, et al. Bivalirudin during primary PCI in acute myocardial infarction. N Engl J Med 2008;358:2218-30.

115. Mehran R, Lansky AJ, Witzenbichler B, et al. Bivalirudin in patients undergoing primary angioplasty for acute myocardial infarction (HORIZONS-AMI): 1-year results of a randomised controlled trial. Lancet 2009;374:1149-59.

116. Schulz S, Richardt G, Laugwitz KL, et al. Prasugrel plus bivalirudin vs. clopidogrel plus heparin in patients with ST-segment elevation myocardial infarction. Eur Heart J 2014:35:2285-94.

117. Shahzad A, Kemp I, Mars C, et al. Unfractionated heparin versus bivalirudin in primary percutaneous coronary intervention (HEAT-PPCI): an open-label, single centre, randomised controlled trial. Lancet 2014;384: $1849-58$.

118. White HD, Aylward PE, Frey MJ, et al. Randomized, double-blind comparison of hirulog versus heparin in patients receiving streptokinase and aspirin for acute myocardial infarction (HERO) Hirulog Early Reperfusion/Occlusion (HERO) Trial Investigators. Circulation 1997;96:2155-61.

119. Antman EM, Anbe DT, Armstrong PW, et al. ACC/AHA guidelines for the management of patients with ST-elevation myocardial infarction-executive summary: a report of the American College of Cardiology/American Heart Association Task Force on Practice Guidelines (Writing Committee to Revise the 1999 Guidelines for the Management of Patients With Acute Myocardial Infarction). Circulation 2004;110:588-636.

120. Bassand JP, Hamm CW, Ardissino D, et al. Guidelines for the diagnosis and treatment of non-ST-segment elevation acute coronary syndromes. Eur Heart J 2007;28:1598-660.

121. Anderson JL, Adams CD, Antman EM, et al. ACC/AHA 2007 guidelines for the management of patients with unstable angina/non ST-elevation myocardial infarction: a report of the American College of Cardiology/American Heart Association Task Force on Practice Guidelines (Writing Committee to Revise the 2002 Guidelines for the Management of Patients With Unstable Angina/Non ST-Elevation Myocardial Infarction): developed in collaboration with the American College of Emergency Physicians, the Society for Cardiovascular Angiography and Interventions, and the Society of Thoracic Surgeons: endorsed by the American Association of Cardiovascular and Pulmonary Rehabilitation and the Society for Academic Emergency Medicine. Circulation 2007; 116:e148-304

122. Kushner FG, Hand M, Smith Jr SC, et al. 2009 Focused Updates: ACC/AHA Guidelines for the Management of Patients With ST-Elevation Myocardial Infarction (updating the 2004 Guideline and 2007 Focused Update) and ACC/AHA/SCAI Guidelines on Percutaneous Coronary Intervention (updating the 2005 Guideline and 2007 Focused Update): a report of the American College of Cardiology Foundation/American Heart Association Task Force on Practice Guidelines. Circulation 2009;120:2271-306 (Erratum in: Circulation. 010 Mar 30;121(12):e257. Dosage error in article text).

123. Castaigne AD, Herve C, Duval-Moulin AM, et al. Prehospital use of APSAC: results of a placebo-controlled study. Am J Cardiol 1989;64:30A-3A (discussion $41 \mathrm{~A}-2 \mathrm{~A})$.

124. Schofer J, Buttner J, Geng G, et al. Prehospital thrombolysis in acute myocardial infarction. Am J Cardiol 1990;66:1429-33.

125. Weaver WD, Cerqueira M, Hallstrom AP, et al. Prehospital-initiated vs. hospital-initiated thrombolytic therapy The Myocardial Infarction Triage and Intervention Trial. JAMA 1993;270:1211-6.

126. Welsh RC, Travers A, Senaratne M, Williams R, Armstrong PW. Feasibility and applicability of paramedic-based prehospital fibrinolysis in a large North American Center. Am Heart J 2006;152:1007-14.

127. Armstrong PW, Gershlick AH, Goldstein P, et al. Fibrinolysis or primary PCI in ST-segment elevation myocardial infarction. N Engl J Med 2013;368:1379-87.

128. Larson DM, Duval S, Sharkey SW, et al. Safety and efficacy of a pharmacoinvasive reperfusion strategy in rural ST-elevation myocardial infarction patients with expected delays due to long-distance transfers. Eur Heart J 2012;33:1232-40.

129. Keeley EC, Boura JA, Grines CL. Primary angioplasty versus intravenous thrombolytic therapy for acute myocardial infarction: a quantitative review of 23 randomised trials. Lancet 2003;361:13-20.

130. Bonnefoy E, Steg PG, Boutitie F, et al. Comparison of primary angioplasty and pre-hospital fibrinolysis in acute myocardial infarction (CAPTIM) trial: a 5-year follow-up. Eur Heart J 2009;30:1598-606.

131. Kalla K, Christ G, Karnik R, et al. Implementation of guidelines improves the standard of care: the Viennese registry on reperfusion strategies in ST-elevation myocardial infarction (Vienna STEMI registry). Circulation 2006;113:2398-405.

132. Terkelsen CJ, Sorensen JT, Maeng M, et al. System delay and mortality among patients with STEMI treated with primary percutaneous coronary intervention. JAMA 2010;304:763-71.

133. Pinto DS, Kirtane AJ, Nallamothu BK, et al. Hospital delays in reperfusion for ST-elevation myocardial infarction: implications when selecting a reperfusion strategy. Circulation 2006;114:2019-25.

134. Madsen MM, Busk M, Sondergaard HM, et al. Does diabetes mellitus abolish the beneficial effect of primary coronary angioplasty on long-term risk of reinfarction after acute ST-segment elevation myocardial infarction compared with fibrinolysis? (A DANAMI-2 substudy). Am J Cardiol 2005;96: 1469-75.

135. Le May MR, So DY, Dionne R, et al. A citywide protocol for primary PCI in ST-segment elevation myocardial infarction. N Engl J Med 2008;358:231-40.

136. Bradley EH, Herrin J, Wang Y, et al. Strategies for reducing the door-to-balloon time in acute myocardial infarction. N Engl J Med 2006;355:2308-20.

137. Bonnefoy E, Lapostolle F, Leizorovicz A, et al. Primary angioplasty versus prehospital fibrinolysis in acute myocardial infarction: a randomised study. Lancet 2002;360:825-9.

138. Armstrong PW. A comparison of pharmacologic therapy with/without timely coronary intervention vs. primary percutaneous intervention early after ST-elevation myocardial infarction: the WEST (Which Early ST-elevation myocardial infarction Therapy) study. Eur Heart J 2006;27:1530-8.

139. Thiele H, Eitel I, Meinberg C et al. Randomized comparison of pre-hospitalinitiated facilitated percutaneous coronary intervention versus primary percutaneous coronary intervention in acute myocardial infarction very early after symptom onset: the LIPSIA-STEMI trial (Leipzig immediate prehospital facilitated angioplasty in ST-segment myocardial infarction). JACC CardiovasC Interv 2011;4:605-14.

140. Andersen HR, Nielsen TT, Rasmussen K, et al. A comparison of coronary angioplasty with fibrinolytic therapy in acute myocardial infarction. N Engl J Med 2003;349:733-42.

141. Dieker HJ, van Horssen EV, Hersbach FM, et al. Transport for abciximab facilitated primary angioplasty versus on-site thrombolysis with a liberal rescue policy: the randomised Holland Infarction Study (HIS). J Thromb Thrombolysis 2006;22:39-45. 
142. Dobrzycki S, Kralisz P, Nowak K, et al. Transfer with GP IIb/IIla inhibitor tirofiban for primary percutaneous coronary intervention vs. on-site thrombolysis in patients with ST-elevation myocardial infarction (STEMI): a randomized open-label study for patients admitted to community hospitals. Eur Heart J 2007;28:2438-48.

143. Grines CL, Westerhausen Jr DR, Grines LL, et al. A randomized trial of transfer for primary angioplasty versus on-site thrombolysis in patients with high-risk myocardial infarction: the Air Primary Angioplasty in Myocardial Infarction study. J Am Coll Cardiol 2002;39:1713-9.

144. Svensson L, Aasa M, Dellborg M, et al. Comparison of very early treatment with either fibrinolysis or percutaneous coronary intervention facilitated with abciximab with respect to ST recovery and infarct-related artery epicardial flow in patients with acute ST-segment elevation myocardial infarction: the Swedish Early Decision (SWEDES) reperfusion trial. Am Heart J 2006;151. 798:e1-7.

145. Vermeer F, Oude Ophuis AJ, vd Berg EJ, et al. Prospective randomised comparison between thrombolysis, rescue PTCA, and primary PTCA in patients with extensive myocardial infarction admitted to a hospital without PTCA facilities: a safety and feasibility study. Heart 1999;82:426-31.

146. Widimsky P, Groch L, Zelizko M, Aschermann M, Bednar F, Suryapranata H. Multicentre randomized trial comparing transport to primary angioplasty vs. immediate thrombolysis vs. combined strategy for patients with acute myocardial infarction presenting to a community hospital without a catheterization laboratory The PRAGUE study. Eur Heart J 2000;21:823-31.

147. Widimsky P, Budesinsky T, Vorac D, et al. Long distance transport for primary angioplasty vs immediate thrombolysis in acute myocardial infarction Final results of the randomized national multicentre trial-PRAGUE-2. Eur Heart J 2003;24:94-104.

148. Van de Werf F, Barron HV, Armstrong PW, et al. Incidence and predictors of bleeding events after fibrinolytic therapy with fibrin-specific agents: a comparison of TNK-tPA and rt-PA. Eur Heart J 2001;22:2253-61.

149. Ellis SG, Tendera M, de Belder MA, et al., Facilitated PCI. In patients with ST elevation myocardial infarction. N Engl J Med 2008;358:2205-17.

150. Itoh T, Fukami K, Suzuki T, et al. Comparison of long-term prognostic evaluation between pre-intervention thrombolysis and primary coronary intervention: prospective randomized trial: five-year results of the IMPORTANT study. Circ J 2010;74:1625-34 (official journal of the Japanese Circulation Society).

151. Kurihara H, Matsumoto S, Tamura R, et al. Clinical outcome of percutaneous coronary intervention with antecedent mutant t-PA administration for acute myocardial infarction. Am Heart J 2004;147:E14.

152. Thiele H, Scholz M, Engelmann L, et al. ST-segment recovery and prognosis in patients with ST-elevation myocardial infarction reperfused by prehospital combination fibrinolysis, prehospital initiated facilitated percutaneous coronary intervention, or primary percutaneous coronary intervention. Am J Cardiol 2006;98:1132-9.

153. Gershlick $A H$, Stephens-Lloyd A, Hughes $S$, et al. Rescue angioplasty after failed thrombolytic therapy for acute myocardial infarction. N Engl J Med 2005;353:2758-68.

154. Scheller B, Hennen B, Hammer B, et al. Beneficial effects of immediate stenting after thrombolysis in acute myocardial infarction. J Am Coll Cardiol 2003; $42: 634-41$

155. Fernandez-Aviles F, Alonso JJ, Castro-Beiras A, et al. Routine invasive strategy within $24 \mathrm{~h}$ of thrombolysis versus ischaemia-guided conservative approach for acute myocardial infarction with ST-segment elevation (GRACIA-1): a randomised controlled trial. Lancet 2004;364:1045-53.

156. Le May MR, Wells GA, Labinaz M, et al. Combined angioplasty and pharmacological intervention versus thrombolysis alone in acute myocardial infarction (CAPITAL AMI study). J Am Coll Cardiol 2005;46:417-24

157. Cantor WJ, Fitchett D, Borgundvaag B, et al. Routine early angioplasty after fibrinolysis for acute myocardial infarction. N Engl J Med 2009·360:2705-18.

158. Bohmer E, Hoffmann P, Abdelnoor M, Arnesen H, Halvorsen S. Efficacy and safety of immediate angioplasty versus ischemia-guided management after thrombolysis in acute myocardial infarction in areas with very long transfer distances results of the NORDISTEMI (NORwegian study on DIstrict treatment of ST-elevation myocardial infarction). J Am Coll Cardiol 2010;55:102-10.

159. Fernandez-Aviles F, Alonso JJ, Pena G, et al. Primary angioplasty vs. early routine post-fibrinolysis angioplasty for acute myocardial infarction with STsegment elevation: the GRACIA-2 non-inferiority, randomized, controlled trial. Eur Heart J 2007;28:949-60.

160. Danchin N, Coste P, Ferrieres J, et al. Comparison of thrombolysis followed by broad use of percutaneous coronary intervention with primary percutaneous coronary intervention for ST-segment-elevation acute myocardial infarction: data from the french registry on acute ST-elevation myocardial infarction (FAST-MI). Circulation 2008;118:268-76.
161. Thiele H, Zeymer U, Neumann FJ, et al. Intraaortic balloon support for myocardial infarction with cardiogenic shock. N Engl J Med 2012;367:1287-96.

162. Hochman JS, Sleeper LA, Webb JG, et al. Early revascularization and long-term survival in cardiogenic shock complicating acute myocardial infarction. JAMA 2006;295:2511-5

163. Larsen JM, Ravkilde J. Acute coronary angiography in patients resuscitated from out-of-hospital cardiac arrest-a systematic review and meta-analysis. Resuscitation 2012;83:1427-33.

164. Spaulding CM, Joly LM, Rosenberg A, et al. Immediate coronary angiography in survivors of out-of-hospital cardiac arrest. N Engl J Med 1997;336:1629-33.

165. Camuglia AC Randhawa VK, Lavi S, Walters DL. Cardiac catheterization is associated with superior outcomes for survivors of out of hospital cardiac arrest: review and meta-analysis. Resuscitation 2014;85:1533-40.

166. Rab T, Kern KB, Tamis-Holland JE, et al. Cardiac arrest: a treatment algorithm for emergent invasive cardiac procedures in the resuscitated comatose patient. J Am Coll Cardiol 2015;66:62-73.

167. Dumas F, Manzo-Silberman S, Fichet J, et al. Can early cardiac troponin I measurement help to predict recent coronary occlusion in out-of-hospital cardiac arrest survivors? Crit Care Med 2012;40:1777-84.

168. Dumas F, Cariou A, Manzo-Silberman S, et al. Immediate percutaneous coronary intervention is associated with better survival after out-of-hospital cardiac arrest: insights from the PROCAT (Parisian Region Out of hospital Cardiac ArresT) registry. Circ Cardiovasc Interv 2010;3:200-7.

169. Bro-Jeppesen J, Kjaergaard J, Wanscher M, et al. Emergency coronary angiography in comatose cardiac arrest patients: do real-life experiences support the guidelines? Eur Heart J Acute Cardiovasc Care 2012;1:291-301.

170. Hollenbeck RD, McPherson JA, Mooney MR, et al. Early cardiac catheterization is associated with improved survival in comatose survivors of cardiac arrest without STEMI. Resuscitation 2014:85:88-95.

171. Dankiewicz J, Nielsen N, Annborn M, et al. Survival in patients without acute ST elevation after cardiac arrest and association with early coronary angiography: a post hoc analysis from the TTM trial. Intensive Care Med 2015;41: 856-64.

172. Noc M, Fajadet J, Lassen JF, et al. Invasive coronary treatment strategies for out-of-hospital cardiac arrest: a consensus statement from the European association for percutaneous cardiovascular interventions (EAPCI)/stent for life (SFL) groups. EuroIntervention 2014;10:31-7.

173. Yusuf S, Peto R, Lewis J, Collins R, Sleight P. Beta blockade during and after myocardial infarction: an overview of the randomized trials. Prog Cardiovasc Dis 1985;27:335-71.

174. Chen ZM, Pan HC, Chen YP, et al. Early intravenous then oral metoprolol in 45,852 patients with acute myocardial infarction: randomised placebocontrolled trial. Lancet 2005;366:1622-32.

175. Teo KK, Yusuf S, Furberg CD. Effects of prophylactic antiarrhythmic drug therapy in acute myocardial infarction an overview of results from randomized controlled trials. JAMA 1993:270:1589-95.

176. Hine LK, Laird N, Hewitt P, Chalmers TC. Meta-analytic evidence against prophylactic use of lidocaine in acute myocardial infarction. Arch Intern Med 1989;149:2694-8

177. ISIS-4 (Fourth International Study of Infarct Survival) Collaborative, Group. ISIS-4: a randomised factorial trial assessing early oral captopril, oral mononitrate, and intravenous magnesium sulphate in 58,050 patients with suspected acute myocardial, infarction. Lancet 1995;345:669-85.

178. Swedberg K, Held P, Kjekshus J, Rasmussen K, Ryden L, Wedel H. Effects of the early administration of enalapril on mortality in patients with acute myocardial infarction results of the Cooperative New Scandinavian Enalapril Survival Study II (CONSENSUS II). N Engl J Med 1992;327:678-84.

179. ACE Inhibitor Myocardial Infarction Collaborative Group. Indications for ACE inhibitors in the early treatment of acute myocardial infarction: systematic overview of individual data from 100,000 patients in randomized trials. Circulation 1998;97:2202-12

180. Pfeffer MA, McMurray JJ, Velazquez EJ, et al. Valsartan, captopril, or both in myocardial infarction complicated by heart failure, left ventricular dysfunction, or both. N Engl J Med 2003;349:1893-906.

181. Patti G, Pasceri V, Colonna G, et al. Atorvastatin pretreatment improves outcomes in patients with acute coronary syndromes undergoing early percutaneous coronary intervention: results of the ARMYDA-ACS randomized trial. J Am Coll Cardiol 2007;49:1272-8.

182. Hulten E, Jackson JL, Douglas K, George S, Villines TC. The effect of early, intensive statin therapy on acute coronary syndrome: a meta-analysis of randomized controlled trials. Arch Intern Med 2006;166:1814-21.

183. Heeschen C, Hamm CW, Laufs U, Snapinn S, Bohm M, White HD. Withdrawal of statins increases event rates in patients with acute coronary syndromes. Circulation 2002;105:1446-52. 